\title{
Upstream and downstream of mTOR
}

\author{
Nissim Hay ${ }^{1,3}$ and Nahum Sonenberg ${ }^{2,4}$ \\ ${ }^{1}$ Department of Biochemistry and Molecular Genetics, University of Illinois at Chicago, Chicago, Illinois 60607, USA; \\ ${ }^{2}$ Department of Biochemistry and McGill Cancer Center, McGill University, Montreal, Quebec, Canada H3G 1Y6
}

\begin{abstract}
The evolutionarily conserved checkpoint protein kinase, TOR (target of rapamycin), has emerged as a major effector of cell growth and proliferation via the regulation of protein synthesis. Work in the last decade clearly demonstrates that TOR controls protein synthesis through a stunning number of downstream targets. Some of the targets are phosphorylated directly by TOR, but many are phosphorylated indirectly. In this review, we summarize some recent developments in this fast-evolving field. We describe both the upstream components of the signaling pathway(s) that activates mammalian TOR (mTOR) and the downstream targets that affect protein synthesis. We also summarize the roles of mTOR in the control of cell growth and proliferation, as well as its relevance to cancer and synaptic plasticity.
\end{abstract}

\section{The upstream regulators of $\mathrm{mTOR}$}

The mammalian target of rapamycin (mTOR) was identified and cloned (Brown et al. 1994; Chiu et al. 1994; Sabatini et al. 1994) shortly after the discovery of the two yeast genes, TOR1 and TOR2, in the budding yeast Saccharomyces cerevisiae during a screen for resistance to the immunosuppressant drug rapamycin (Kunz et al. 1993; Helliwell et al. 1994). Rapamycin was originally isolated from a strain of the soil bacterium, Streptomyces hygroscopicus. It acts by forming an inhibitory complex with its intracellular receptor, the FK506-binding protein, FKBP12, which binds a region in the $\mathrm{C}$ terminus of TOR proteins termed FRB (FKB12-rapamycin binding), thereby inhibiting TOR activity (Chen et al. 1995; Choi et al. 1996). The mammalian ortholog of the yeast TOR proteins was independently cloned and identified by using an FKBP12-rapamycin affinity purification by four groups and named FRAP (FKBP-rapamycin-associated protein) RAFT1 (rapamycin and FKBP target), or RAPT1 (rapamycin target; Brown et al. 1994; Chiu et al. 1994; Sabatini et al. 1994; Sabers et al. 1995). Mammalian genomes, as well as those of other metazoans, encode a single TOR protein with a similar structure ex-

[Keywords: Akt; TSC1/TSC2; Rheb; 4E-BP; S6K; eIF4E] Correspondence.

${ }^{3}$ E-MAIL nhay@uic.edu; FAX (312) 355-2032

${ }^{4}$ E-MAIL nahum.sonenberg@mcgill.ca; FAX (514) 398-1287.

Article and publication are at http://www.genesdev.org/cgi/doi/10.1101/ gad.1212704. hibiting $\sim 42 \%$ amino acid sequence identity to the yeast TOR proteins. TORs are high molecular-weight proteins that contain several distinct and conserved structural domains. mTOR contains 2549 amino acids and comprises several conserved structural domains (Fig. 1). The $\mathrm{N}$ terminus possesses 20 tandem HEAT (for Huntignton, EF3, A subunit of PP2A, TOR1) repeats. Each HEAT repeat consists of two $\alpha$ helices of $\sim 40$ amino acids, each with a specific pattern of hydrophobic and hydrophilic residues. Tandem HEAT repeats are present in many proteins and are implicated in protein-protein interactions (Andrade and Bork 1995). The C-terminal half of mTOR contains the kinase domain, which has sequence similarity with the catalytic domain of phosphatidylinositol 3-kinase (PI3K). However, there is no experimental evidence that it displays lipid kinase activity, and in this respect, it is similar to other protein kinases such as ATM and ATR that also posses a structural domain similar to PIK and belong to a family of kinases termed PIKK (PI3K-related kinase). Immediately upstream of the catalytic domain is the FRB domain. In addition, mTOR contains a relatively large FAT (for FRAP, ATM, TRAP) domain, which is also present in other PIKK proteins (Bosotti et al. 2000). The C-terminal end contains another FAT domain, designated FATC (Fig. 1). The FATC domain is absolutely necessary for mTOR activity, and the deletion of even a single amino acid from this domain abrogates the activity (Peterson et al. 2000; Takahashi et al. 2000). It has been proposed that the FATC and FAT domains interact to yield a configuration that exposes the catalytic domain. mTOR also contains a putative negative regulatory domain (NRD) between the catalytic and FATC domains (Fig. 1; Sekulic et al. 2000).

A search for readouts of mTOR activity in vivo and in vitro revealed that $\mathrm{mTOR}$ can be autophosphorylated via its intrinsic serine/threonine kinase activity (Brown et al. 1995). mTOR regulates protein synthesis through the phosphorylation and inactivation of the repressor of mRNA translation, eukaryotic initiation factor 4E-binding protein (4E-BP1), and through the phosphorylation and activation of S6 kinase (S6K1). These two downstream effectors of mTOR whose phosphorylation is inhibited by rapamycin in vivo, can be phosphorylated by recombinant mTOR in vitro (Brunn et al. 1997; Burnett et al. 1998). Moreover, substitution of Asp 2338 with alanine in the catalytic domain of MTOR is sufficient to inhibit mTOR kinase activity toward S6K1 and 4E-BP1 


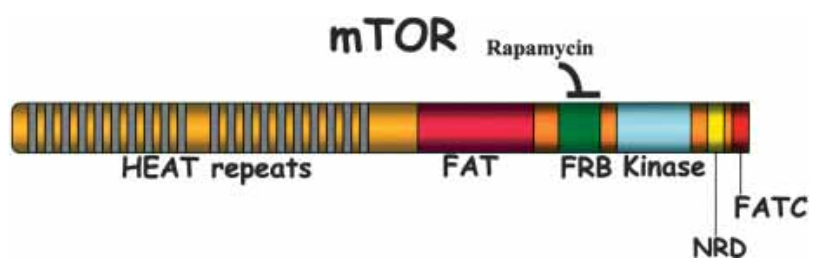

Figure 1. The primary structure of mTOR. See text for details.

in vivo and in vitro (Brown et al. 1995; Brunn et al. 1997). Thus, S6K1 or 4E-BP1 phosphorylation is often used as an in vivo readout of mTOR activity. However, the question of whether the intrinsic kinase activity of mTOR is sufficient for its full activity in vivo has not been resolved. Furthermore, it is not clear whether mTOR may also serve as a scaffold for other proteins with catalytic activity, such as kinases and phosphatases that may regulate its overall activity in vivo.

The activity of the two yeast TOR proteins is regulated by nutrients. TOR proteins are activated when yeast cells are grown on nitrogen-rich sources like glutamine, and become inactive upon depletion of such sources (for review, see Hall 1996; Schmelzle and Hall 2000; Crespo and Hall 2002). In metazoans, growth factors and cytokines control intracellular metabolic pathways. For instance, in mammalian cells, growth factors, and cytokines, in addition to regulating nutrient uptake, also activate signaling pathways that act in parallel or in concert with nutrients. The regulation of mTOR is probably one of the best examples of evolutionarily conserved nutrient-mediated regulation, functioning in concert with the evolved metazoan-signaling regulatory pathways mediated by growth factors. The regulation of mTOR activity by nutrients, growth factors, and energy metabolism is discussed below.

\section{Control by nutrients}

The molecular mechanisms by which TOR proteins sense nutrient availability became clearer following the isolation of protein complexes associated with TOR1 and TOR2 from the budding yeast $S$. cerevisiae (Loewith et al. 2002). These complexes contain, in addition to TOR1 and TOR2, five other proteins. Three of these, AVO1, AVO2, and AVO3, interact only with TOR2, whereas two, LST8 and Kontroller of Growth-1 (KOG1), interact independently with either TOR1 or TOR2 (Loewith et al. 2002). However, the integrity of these complexes appears to be unaffected by either rapamycin or nutrient starvation (Loewith et al. 2002). LST8 and KOG1 have mammalian orthologs that were independently isolated following biochemical fractionation of mTOR-associated proteins (Hara et al. 2002; Kim et al. 2002, 2003). The phenotype of KOG1 deficiency in yeast resembles the phenotype of either TOR deficiency or rapamycin-treated cells, suggesting that KOG1 is a positive regulator of TOR (Loewith et al. 2002). Analysis of several LST8 mutants suggests that LST8 also is a positive regulator of TOR (Chen and Kaiser 2003). More re- cently, a complex similar to the yeast TOR2-specific complex was described in mammals. This complexwhich, like its counterpart in yeast, is rapamycin-insensitive-contains the orthologs of AVO3 (mAVO3 or Rictor) and LST8 (Sarbasov et al. 2004; M. Hall, pers. comm.) Like the TOR2-specific complex in yeast, this compex appears to regulate the actin cytoskeleton (Schmidt et al. 1996; Loewith et al. 2002; Sarbassov et al. 2004; M. Hall, pers. comm.).

The mammalian ortholog of KOG1 is Raptor (regulatory associated protein of TOR; Hara et al. 2002; Kim et al. 2002), a conserved 150-kDa protein that also binds the downstream effectors of $\mathrm{mTOR}, \mathrm{S} 6 \mathrm{~K} 1$, and 4E-BP1 (see below; Hara et al. 2002; Nojima et al. 2003). All Raptor homologs contain a unique conserved region in the $\mathrm{N}$ terminal half, followed by three HEAT repeats and seven WD-40 repeats in the C-terminal half. The $\mathrm{N}$-terminal domain of mTOR containing the HEAT repeats is required for the efficient interaction with Raptor, to which it binds avidly; however, the C-terminal half of mTOR can also bind weakly to Raptor (Kim et al. 2002). Multiple mutations in Raptor in both the conserved N-terminal region and within the HEAT repeats interfere with its binding to mTOR, suggesting that Raptor interacts with mTOR through multiple contact points (Kim et al. 2002). Like KOG1 in yeast, the Caenorhabditis elegans ortholog of Raptor is necessary for TOR activity (Hara et al. 2002), and knockdown experiments of Raptor by RNAi in mammalian cells also suggest its positive role in mTOR activity (Hara et al. 2002; Kim et al. 2002). Although Raptor is normally a positive regulator of mTOR, one report indicates that, upon nutrient deprivation, Raptor-mTOR association is stabilized in a manner that inhibits mTOR kinase activity (Kim et al. 2002).

Biochemical analysis also has led to the identification of the mammalian ortholog of LST8 (mLST8) that was previously identified as $\mathrm{G}$ protein $\beta$-subunit-like protein (GßL; Kim et al. 2003). The 36-kDa mLST8/GßL contains seven WD-40 repeats and, like Raptor, is conserved among all eukaryotes. It interacts specifically with the kinase domain of mTOR (independently of Raptor) and plays a positive role in mTOR activation by nutrients (Kim et al. 2003). mLST8/GßL stabilizes mTOR-Raptor association; thus, mLST8/G $\beta \mathrm{L}$, Raptor, and mTOR are likely to comprise a nutrient-sensitive mTOR complex, whereby mLST8/G $\beta L$ regulates the stability of the mTOR-Raptor association under different nutrient conditions (Kim et al. 2003). The identification of the mLST8/GßL-mTOR-Raptor complex does not explain the exact mechanism by which mTOR senses nutrient availability. However, Sabatini and colleagues (Kim et al. 2002 , 2003) suggested that the nature of the mTORRaptor complex changes upon amino acid deprivation; if indeed true, then this finding may partially explain the effect of amino acids on mTOR activity.

Raptor appears to serve as an adaptor protein that recruits mTOR substrates. It binds S6K1 and 4E-BP1, both downstream effectors of mTOR, and is necessary for the in vitro phosphorylation of 4E-BP1 by mTOR and for the efficient phosphorylation of S6K1 (Beugnet et al. 2003; 
Choi et al. 2003; Nojima et al. 2003; Schalm et al. 2003). The interaction of Raptor with S6K1 and 4E-BP1 is mediated by a 5 amino acid motif termed TOS (TOR signaling) that is present in the $\mathrm{N}$ termini of S6K1 and 4E-BP1 (Schalm and Blenis 2002). Mutations in the TOS motif markedly inhibit mTOR-mediated phosphorylation of 4E-BP1 (Beugnet et al. 2003; Choi et al. 2003; Nojima et al. 2003; Schalm et al. 2003). In contrast to the data reported for yeast TOR (Loewith et al. 2002), rapamycin disrupts the mTOR-Raptor interaction (Kim et al. 2002; Oshiro et al. 2004), thereby preventing the ability of mTOR to phosphorylate S6K and 4E-BP.

Taken together, the findings described above support a model whereby a change in the configuration of the mTOR-Raptor complex, which is mediated by nutrient conditions such as amino acid availability, affects the ability of mTOR to interact with and phosphorylate its substrates (Fig. 2). In the absence of amino acids, the mTOR-mLST8-Raptor complex precludes mTOR from binding avidly to its substrates and/or prevents the access of mTOR (or mTOR-associated kinases) to the substrates. Conversely, in the presence of amino acids, a conformational change promotes efficient interaction between Raptor and mTOR substrates and/or increased accessibility of the substrates to mTOR and its associated kinases. This model does not explain how amino acids elicit these putative conformational changes in mTOR-Raptor complex, and further studies are required to address this question and verify this model. In fact, recent studies show that whereas rapamycin induces mTOR-Raptor dissociation, amino acid deprivation does not alter mTOR-Raptor association (Oshiro et al. 2004).

\section{Control by growth factors}

PI3K/PTEN As described above, mTOR activity is regulated by growth factors. Insulin and other growth factors dramatically increase the phosphorylation of S6K1 and 4E-BP1 in a rapamycin-sensitive manner. Mutations in the PDGF receptor that prevent the recruitment and activation of phosphoinositide-3-OH kinase (PI3K) also inhibit S6K1 phosphorylation by PDGF (Chung et al. 1994). In addition, a mutated insulin recep-

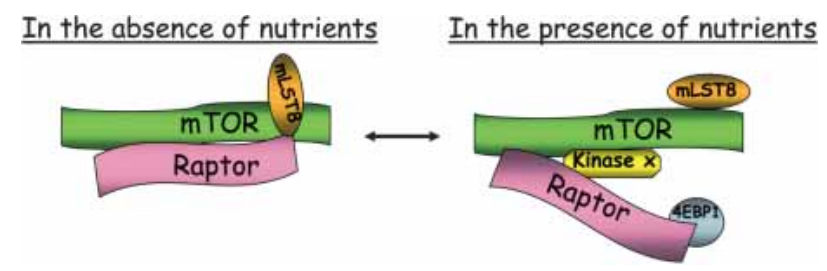

Figure 2. A model of how the mTOR-Raptor interaction may regulate $\mathrm{mTOR}$ activity in response to nutrients. In the absence of nutrients, a tight interaction between mTOR, Raptor, and mLST8 prevents the access of mTOR to its targets. In the presence of nutrients, a conformational change may disrupt Raptor/ mLST8 interaction and enables the accessibility of mTOR (or an associated kinase) to its targets, 4E-BP1 or S6K1, which are bound to raptor. tor substrate 1 (IRS-1) that only activates PI3K is sufficient to promote phosphorylation of 4E-BP1 induced by insulin (Chung et al. 1994; Mendez et al. 1996). These results provide strong evidence that growth factor-induced activation of mTOR is mediated by PI3K. This conclusion was further substantiated by experiments using the pharmacological inhibitors wortmannin and LY294002, which inhibit PI3K and the phosphorylation of S6K1 and 4E-BP1 (Cheatham et al. 1994; Chung et al. 1994; Brunn et al. 1996; von Manteuffel et al. 1996). One significant concern often raised regarding these studies is that mTOR activity itself can be inhibited in vitro with high concentrations of these pharmacological inhibitors. However, it is well accepted that PI3K is a bona fide upstream positive regulator of $\mathrm{mTOR}$, because much lower concentrations of wortmannin are required to inhibit mTOR activity in vivo using 4E-BP1 and S6K1 phosphorylation as readouts (Brunn et al. 1996). Furthermore, overexpression of an activated catalytic subunit of PI3K, p110, in HEK-293 cells induces 4E-BP1 phosphorylation in the absence of growth factors or insulin and in a rapamycin-sensitive manner (Gingras et al. 1998). In addition, overexpression of dominant-negative forms of $\mathrm{p} 85$, the regulatory subunit of $\mathrm{PI} 3 \mathrm{~K}$, inhibits insulin-induced phosphorylation of S6K1 (Sharma et al. 1998; Ueki et al. 2000). These results are consistent with the observation that PTEN-deficient cells have high levels of 4EBP1 and S6K1 phosphorylation (Neshat et al. 2001; Podsypanina et al. 2001). PTEN (phosphatase and tensin homolog on chromosome 10) is a phosphatidylinositol-3 phosphatase that counteracts PI3K activity by dephosphorylating phosphatidylinositol-3,4-bisphosphate (PIP2) and phosphatidylinositol-3,4,5-triphosphate (PIP3) that are generated by PI3K (Fig. 3). Further support for the positive role of PI3K on TOR activity comes from genetic analyses in Drosophila. As in mammalian cells, the Drosophila TOR (dTOR) appears to be a downstream effector of the insulin/IGF-1 receptor. Drosophila cells lacking dTOR are relatively small due to reduced protein synthesis, whereas cells lacking Drosophila PTEN (dPTEN) are larger. Cells deficient in both dPTEN and dTOR display a phenotype similar to that of cells deficient in dTOR alone, indicating that dTOR is epistatic to dPTEN and acts downstream of PI3K (Oldham et al. 2000; Zhang et al. 2000).

Akt The serine/threonine protein kinase Akt, also known as protein kinase B (PKB), a downstream effector of PI3K, has emerged as a critical mediator of mTOR activity. Mammalian cells express three separate Akt proteins encoded by different genes. The rate-limiting step in Akt activation is the binding of PIP3 to the pleckstrin homology $(\mathrm{PH})$ domain of Akt and the subsequent translocation of Akt to the plasma membrane (Kandel and Hay 1999; Brazil and Hemmings 2001; Scheid and Woodgett 2001). Akt is then phosphorylated by 3-phosphoinositide-dependent kinase-1 (PDK1) and by another as yet unknown PI3K-dependent kinase (Fig. 3). Both phosphorylation events are required for full activation of Akt. Overexpression of an activated form of Akt in HEK- 


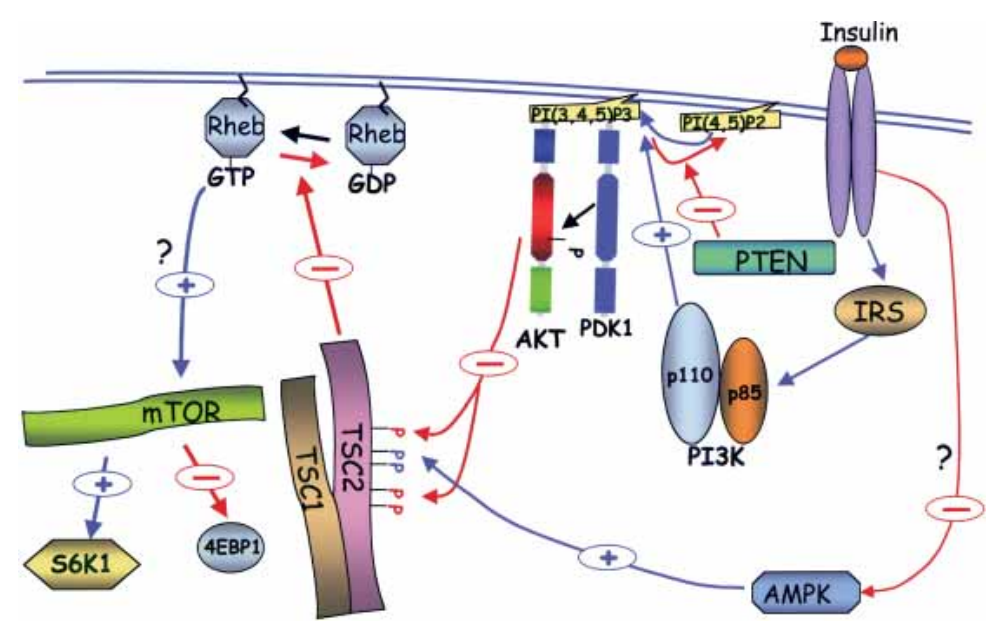

Figure 3. The regulation mTOR activity by growth factors is mediated by the PI3K/Akt signaling pathway leading to phosphorylation and inhibition of TSC2 by Akt and to the subsequent activation of Rheb, which activates mTOR by an as yet unknown mechanism. In addition, TSC2 is activated by AMPK (see text for details). (+) Activation; (-) inhibition.
293 cells promotes 4E-BP1 phosphorylation in the absence of growth factors and in a wortmannin-resistant and rapamycin-sensitive manner (Gingras et al. 1998). Furthermore, overexpression of a dominant-negative form of Akt impairs insulin-mediated phosphorylation of 4E-BP1 (Gingras et al. 1998). These findings unequivocally place Akt upstream of mTOR and also are consistent with several studies in Drosophila. Overexpression of Drosophila Akt (dAkt) increases organ and cell size (Verdu et al. 1999) and a nonphosphorylatable form of Drosophila 4E-BP suppresses this phenotype (Miron et al. 2001), whereas the loss of dAkt reduces cell and body size (Scanga et al. 2000). Recent knockdown experiments using RNAi in S2 Drosophila tissue culture cells also provide evidence that Akt is a positive regulator of mTOR (Lizcano et al. 2003; Miron et al. 2003). Studies with mice lacking two (Akt1 and Akt2) of the three Akt proteins provide the first genetic evidence that Akt functions upstream of mTOR in mammalian cells (Peng et al. 2003). Interestingly, S6K1 phosphorylation is not decreased as markedly as 4E-BP1 phosphorylation in cells lacking Akt1 and Akt2, suggesting that Akt3 activity is sufficient to promote S6K1 phosphorylation, and that 4E-BP1 phosphorylation is more dependent than S6K1 phosphorylation on Akt activity. The upstream positive regulatory role of Akt in mTOR activation has been questioned, first, because S6K1 phosphorylation does not always correlate with Akt activity both in mammalian cells and in Drosophila (Dufner et al. 1999; Radimerski et al. 2002), and second, because it was not clear how Akt functionally interacts with mTOR. Both insulin and Akt induce phosphorylation of mTOR in vivo. mTOR possesses two adjacent phosphorylation sites (Thr 2446 and Ser 2448) for Akt, and Ser 2448 is phosphorylated by Akt in vitro and in vivo (Scott et al. 1998; Nave et al. 1999; Sekulic et al. 2000; Reynolds et al. 2002). Interestingly, Thr 2446 and Ser 2448 reside within the putative NRD of mTOR (Fig. 1). The significance of this phosphorylation is in question, however, because substitution of Thr 2446 and Ser 2448 with alanine does not affect mTOR activity (Sekulic et al. 2000). Moreover, these Akt phosphorylation sites are not conserved in dTOR.
TSC1/TSC2 A major breakthrough in the understanding of how growth factors and Akt regulate mTOR activity was achieved by the discovery that the TSC1 and TSC2 proteins are upstream regulators of mTOR. TSC1 (also known as hamartin) and TSC2 (also known as tuberin) are encoded by the tuberous sclerosis complex 1 (TSC1) and tuberous sclerosis complex 2 (TSC2) genes, respectively, which are associated with the dominant genetic disorder, tuberous sclerosis complex (TSC), characterized by hamartomas with very large cells in many organs (Cheadle et al. 2000). Mutations in TSC1 and TSC2 contribute to inherited and sporadic TSC (The European Chromosome 16 Tuberous Sclerosis Consortium 1993; van Slegtenhorst et al. 1997).

Mutations in Drosophila TSC1 or TSC2 cause increased cell and organ size similar to that caused by mutation of dPTEN (Gao and Pan 2001; Potter et al. 2001; Tapon et al. 2001). TSC1 and TSC2 interact through their $\mathrm{N}$ termini and appear to function as a heterodimer because overexpression of Drosophila TSC1 or TSC2 alone does not elicit a phenotype, whereas overexpression of both dramatically slows cell growth (Gao and Pan 2001; Potter et al. 2001; Tapon et al. 2001). The similarity between the phenotypes caused by TSC1/TSC2 and dPTEN deficiencies in Drosophila prompted genetic epistasis experiments, which showed that TSC1 and TSC2 function between Akt and S6K in the insulin-signaling pathway (Potter et al. 2001). These observations and the fact that S6K1 is highly phosphorylated in mammalian cells lacking a functional TSC1 or TSC2 (Goncharova et al. 2002; Kwiatkowski et al. 2002) provide potential links between Akt and TSC1/TSC2 and between mTOR and TSC1/TSC2. These links were established by the finding that TSC2 is directly phosphorylated by Akt in vitro and in vivo (Inoki et al. 2002; Manning et al. 2002). There are several potential Akt phosphorylation sites in mammalian TSC2 and Drosophila TSC2 (dTSC2). Ser 939, Ser 1130, and Thr 1462 in human TSC2 and two conserved residues in Drosophila TSC2 are phosphorylated by Akt (Inoki et al. 2002; Manning et al. 2002; Potter et al. 2002). Further analyses of TSC2-deficient cells, as well as TSC1 and 
TSC2 overexpression experiments, clearly demonstrate that the TSC1/TSC2 heterodimer is an upstream negative regulator of mTOR (Gao et al. 2002; Inoki et al. 2002; Jaeschke et al. 2002; Manning et al. 2002; Tee et al. 2002). Both S6K1 and 4E-BP1 are constitutively phosphorylated in a rapamycin-sensitive manner in cells deficient for TSC2, and overexpression of both TSC1 and TSC2 in HEK-293 cells impairs insulin-stimulated phosphorylation of S6K1 and 4E-BP1. Moreover, a mutant of TSC2 in which Akt-phosphorylated residues were substituted by alanine acts as a dominant inhibitor of mTOR activity by blocking its activation in response to growth factors (Inoki et al. 2002; Manning et al. 2002). The inhibitory role of Akt phosphorylation on TSC2 activity is also supported by studies in which a nonphosphorylatable mutant of dTSC2 inhibited Akt-stimulated growth in the Drosophila eye (Potter et al. 2002). In summary, the observations described above provide strong evidence that Akt activates mTOR, at least in part, through the phosphorylation and inactivation of TSC2.

An intriguing phenomenon of a negative regulatory loop was observed in TSC2- or TSC1-deficient cells, in which Akt activity mediated by insulin and other growth factors is significantly diminished (Jaeschke et al. 2002; Kwiatkowski et al. 2002; Zhang et al. 2003a). This negative regulatory loop may have evolved to coordinate mTOR and Akt functions (see below).

Despite the abundance of data implying that Akt functions by relieving the inhibitory effect of TSC1/TSC2 on mTOR, the precise mechanism by which Akt phosphorylation affects the function of TSC1/TSC2 heterodimer is not clear. Some studies suggest that TSC2 phosphorylation disrupts TSC1/TSC2 heterodimer formation and accelerates degradation of TSC1 and TSC2 (Inoki et al. 2002; Potter et al. 2002). However, other studies do not support such a model (Dan et al. 2002; Manning et al. 2002). Binding of 14-3-3 proteins to Akt phosphorylation sites on TSC2 has been suggested to inhibit TSC2 activity (Liu et al. 2002; Nellist et al. 2002). In contrast, other studies showed that 14-3-3 proteins bind to other sites that were not phosphorylated by Akt (Li et al. 2002; Shumway et al. 2003).

Another unresolved question is whether TSC2 phosphorylation by Akt is sufficient to fully activate mTOR. mTOR activity, as measured by 4E-BP1 phosphorylation, is markedly decreased in Akt1/Akt2-deficient cells, although TSC2 phosphorylation is not substantially decreased (Peng et al. 2003). Also, it remains to be documented that an Akt phosphomimetic TSC2 mutant, when expressed in TSC2 null cells, is inert and incapable of negating the constitutive S6K1- and 4E-BP1-mediated phosphorylation observed in these cells.

Rheb Following the finding that the TSC1/TSC2 heterodimer is an upstream negative regulator of $\mathrm{mTOR}$, studies were initiated to decipher the mechanism by which this heterodimer exerts its effect on mTOR. The 130-kDa TSC1 contains a coiled-coil domain in its C terminus that binds ezrin-radixin-moesin actin-binding proteins implicated in signaling to the cytoskeleton
(Lamb et al. 2000; Haddad et al. 2002). The 200-kDa TSC2 contains a leucine zipper in its $\mathrm{N}$ terminus that is required for interaction with TSC1, and its $\mathrm{N}$ terminus is homologous to the GTPase-activating protein (GAP) of the small GTPase Rap. In early studies, TSC2 was shown to weakly increase the intrinsic GTPase activity of the small GTPases Rap1 and Rab5 (Wienecke et al. 1995; Xiao et al. 1997). This provided the first clue as to the enzymatic activity of the TSC1/TSC2 heterodimer, suggesting that it acts as a GP for a small GTPase. Subsequently, a genome-wide screen for effectors of cell growth in Drosophila uncovered the small GTPase Rheb (Ras homolog enriched in brain; Saucedo et al. 2003; Stocker et al. 2003). When overexpressed in mammalian cells, Rheb is primarily in the GTP-bound activated state (Im et al. 2002).

Human and mouse cells have two Rheb genes, Rheb1 and Rheb2 (Patel et al. 2003). Epistasis analyses in Drosophila suggest that Rheb functions downstream of PI3K/Akt and upstream of TOR and is epistatic over TSC1 and TSC2 (Saucedo et al. 2003; Stocker et al. 2003). A gene knockdown screen using RNAi in Drosophila S2 cells showed that Rheb knockdown inhibits S6K1 phosphorylation, whereas the knockdown of 17 other GTPases did not have such an effect (Zhang et al. 2003b). In parallel, biochemical analysis of several small GTPases in mammalian cells showed that TSC2 exhibits a selective GAP activity toward Rheb (Castro et al. 2003; Garami et al. 2003; Inoki et al. 2003a) and that Rheb binds TSC2 (Castro et al. 2003). Insulin increases the relative amount of endogenous GTP-bound Rheb in a wortmannin-sensitive manner, and the level of GTP-bound Rheb is higher in TSC2 null cells deprived of serum compared with wild-type cells (Garami et al. 2003). In contrast, overexpression of TSC1 and TSC2 decreases the ratio of GTP- to GDP-bound Rheb (Castro et al. 2003; Garami et al. 2003; Tee et al. 2003b), which is alleviated upon mutation of the TSC2 GAP domain (Garami et al. 2003; Tee et al. 2003b; Zhang et al. 2003b). These results provide strong evidence that Rheb is a downstream effector of the TSC1/TSC2 heterodimer and that TSC2 acts as a GAP for Rheb, thereby negatively regulating its activity.

Overexpression of Rheb in mammalian cells leads to the activation of mTOR in the absence of growth factors or in the presence of wortmannin, as measured by S6K1 and 4E-BP1 phosphorylation (Inoki et al. 2002; Castro et al. 2003; Garami et al. 2003; Tee et al. 2003b). Furthermore, overexpression of a dominant-negative form of Rheb blocks activation of mTOR by growth factors and insulin (Tabancay et al. 2003). These results demonstrate that Rheb is an upstream positive regulator of mTOR that acts downstream of TSC1/TSC2, PI3K, and Akt. However, the effect of Akt on the GAP activity of TSC2 or the level of GTP-bound Rheb has not been documented.

Strikingly, there is increased Akt activity in Rheb-deficient Drosophila cells, in which TOR activity is decreased (Stocker et al. 2003). Consistent with these findings, Akt activity is down-regulated in Drosophila cells 
in which TOR is activated by overexpression of Rheb (Stocker et al. 2003). This situation is similar to that in TSC2 null cells, in which mTOR is constitutively activated (Jaeschke et al. 2002; Kwiatkowski et al. 2002; Zhang et al. 2003a). This apparent interplay between TOR and Akt activities is probably mediated by a feedback loop mechanism that appears to be conserved in both mammals and Drosophila.

Although it is established that TSC2 possesses GAP activity toward Rheb, there are conflicting reports regarding the role of TSC1 in this regard. Some studies show that the expression of both TSC2 and TSC1 is required for efficient GAP activity (Garami et al. 2003; Tee et al. 2003b; Zhang et al. 2003b), whereas others show that TSC2 alone is sufficient (Castro et al. 2003; Inoki et al. 2003a). In addition, it is not clear how Rheb affects $\mathrm{mTOR}$ and whether this effect is direct or indirect through other effectors. Also, it is not clear whether a positive regulator of Rheb exists. In general, small GTPases are positively regulated by their cognate guanine nucleotide exchange factors (GEFs) that counteract GAP activity. Because cellular Rheb is mostly in the GTP-bound form and has relatively low intrinsic GTPase activity, it is not clear whether GDP-for-GTP exchange requires a GEF in this case.

Collectively, the findings described above define a linear pathway of mTOR activation by growth factors, from growth factor receptor activation to the activities of PI3K, Akt, TSC1/TSC2, and finally from Rheb to mTOR (Fig. 3).

PLD1 Another mode of mTOR regulation by growth factors was reported to occur via phosphatidic acid (PA). Upon growth factor stimulation, the intracellular level of PA increases via phospholipase D (PLD) activity. PA was shown to bind the mTOR FRB domain and activates mTOR (Fang et al. 2001). It was recently shown that this activation is mediated by PLD1, which is activated by growth factors via the small GTPase, Cdc42 (Fang et al. 2003). It is not clear whether this mode of regulation is independent of mTOR activation via PI3K/Akt, TSC1/ TSC2, and Rheb. The recent observation that overexpression of the TSC1/TSC2 heterodimer impairs the PAmediated activation of mTOR (Tee et al. 2003a) suggests an interplay between the two pathways, whereby the inactivation of $\mathrm{mTOR}$ via the TSC1/TSC2 heterodimer is dominant over the activation by Cdc42/PLD1. In addition, TSC2 appears to be a target for kinases other than Akt. For instance, TSC2 can be inactivated via phosphorylation by PKC and MAPK (Tee et al. 2003a). How these kinases affect TSC2 activity is not clear, but one possibility is that they phosphorylate sites that are recognized by $14-3-3$ proteins, leading to the sequestration of TSC2.

\section{Control by energy metabolism}

mRNA translation and ribosomal biogenesis, two processes that are strongly affected by mTOR, consume high levels of cellular energy (see below for a more detailed description). This raises the possibility that mTOR activity is linked to cellular energy status (Dennis et al. 2001). The ability of insulin to activate mTOR is impaired upon a reduction in cellular ATP levels by reduced glucose availability or the inhibition of mitochondrial respiration, suggesting that cellular energy impacts mTOR activity (Dennis et al. 2001). The effect of intracellular ATP levels on mTOR activity has been attributed to the reported high dissociation constant of mTOR for ATP (Dennis et al. 2001). However, as reduced glucose availability decreases ATP levels only by about twofold, this is unlikely to be the major mechanism by which ATP affects mTOR activity.

The 5'AMP-activated protein kinase (AMPK) is regulated by even moderate changes in ATP levels and can sense the cellular AMP/ATP ratio. AMPK activity increases upon decline of the intracellular ATP level (with a concomitant increase in the AMP level; Hardie et al. 1998; Kemp et al. 1999). AMPK activation leads to a decrease in mTOR activity as measured by S6K1 phosphorylation (Kimura et al. 2003). Similar to the effect of glucose deprivation, exposure of cells to 5-aminoomidazole-4-carboxyamide (AICAR), which activates AMPK, impairs insulin-mediated phosphorylation of S6K1 (Kimura et al. 2003). This effect is dependent on mTOR because the phosphorylation of a variant of S6K1 that is resistant to rapamycin is not affected by AICAR. Furthermore, expression of an activated form of AMPK decreases S6K1 phosphorylation, whereas a dominantnegative form of AMPK increases S6K1 phosphorylation (Kimura et al. 2003). These results provide evidence for a link between intracellular ATP levels, AMPK, and mTOR activity, whereby AMPK senses a decrease in cellular ATP and becomes activated to phosphorylate effectors that inhibit mTOR activity. Recently, TSC2 was identified as such an effector (Inoki et al. 2003b). TSC2 contains multiple AMPK consensus phosphorylation sites, and two of these sites are phosphorylated by AMPK, both in vitro and in vivo (Inoki et al. 2003b). mTOR activity in TSC2 null cells is more refractive to energy deprivation compared with wild-type cells, and expression of a TSC2 mutant in which AMPK-targeted residues are substituted by alanine renders the phosphorylation of S6K1 more resistant to glucose deprivation. These results suggest that AMPK activates TSC2 (Inoki et al. 2003b).

The results described above imply that energy metabolism and protein synthesis are tightly coupled. This coupling is mediated by AMPK via activation of TSC2. However, the mechanism by which TSC2 activity is affected by AMPK-mediated phosphorylation and whether TSC2 GAP activity is increased by this phosphorylation have not been determined. In addition, these results do not completely exclude the possibility that there are other mechanisms by which intracellular ATP levels affect mTOR activity, especially as the activity is partially sensitive to energy deprivation in TSC2 null cells (A. HahnWindgassen and N. Hay, unpubl.). Interestingly, mTOR itself contains several putative phosphorylation sites 
for AMPK (N. Hay, unpubl.). It was recently shown that AMPK phosphorylates Thr 2446 in the putative NRD of mTOR, thereby restricting the ability of Akt to phosphorylate Ser 2448 (Cheng et al. 2004).

The interplay between nutrient and growth factors controls

The upstream regulatory pathways that are mediated by amino acid availability and by growth factors could be viewed as two separate pathways leading to mTOR activation. However, several studies suggest cross-talk between these two pathways and/or convergence into the same upstream regulatory factors. For instance, overexpression of TSC1 and TSC2 blocks amino acid-induced activation of mTOR (Tee et al. 2002), and deletion of TSC2 renders $\mathrm{mTOR}$ resistant to amino acid deprivation (Gao et al. 2002). Furthermore, overexpression of Rheb is able to bypass the inhbition of mTOR activity by amino acid deprivation (Garami et al. 2003). However, a more recent study using TSC2 null cells showed that mTOR is still sensitive to amino acid withdrawal in these cells (Zhang et al. 2003a). In addition, the yeast $S$. cerevisiae, in which TOR activity is regulated solely by nutrients, does not have TSC1 and TSC2 orthologs. This is also the case for C. elegans, in which there is thus far no evidence that TOR is regulated by growth factors (Long et al. 2002). Surprisingly, however, the yeast Schizosaccaromyces pombe has TSC1 and TSC2 orthologs, and mutants thereof are defective in nutrient uptake (Matsumoto et al. 2002; van Slegtenhorst et al. 2004). Furthermore, Rheb deficiency in $S$. pombe causes a growth-arrest phenotype similar to that mediated by nitrogen starvation (Mach et al. 2000). A dominant-negative mutant of Rheb in $S$. pombe rescues the phenotype of TSC2 null cells (van Slegtenhorst et al. 2004), suggesting that, as in mammalian cells, TSC2 is an upstream negative regulator of Rheb. These observations in $S$. pombe support the notion that the TSC1/TSC2 heterodimer may constitute the convergence point for both growth factor- and nutrient-related controls of mTOR activity.

As described above, the AMPK-mediated role of TSC2 in sensing glucose levels is more established than its role in sensing amino acids availability (Inoki et al. 2003b). Interestingly, mTOR-Raptor association is also sensitive to glucose availability (Kim et al. 2002). However, it remains to be demonstrated whether the association of Raptor and mLST8 with mTOR can be regulated by growth factors.

\section{Downstream targets of mTOR}

The major targets of mTOR appear to be components of the translation machinery, and in particular, those responsible for ribosome recruitment to mRNA. We will therefore begin with a short introduction to the mammalian recruitment of ribosomes to mRNA. Translation is regulated in most instances at the step during which a ribosome is recruited to the $5^{\prime}$ end of an mRNA, positioned at a start codon (Gingras et al. 1999b). Ribosome binding is facilitated by a number of translation initiation factors that guide the ribosome to an mRNA 5' end, except for mRNAs, which initiate by binding to an internal ribosome-binding site (IRES). The $5^{\prime}$ end of all nuclear-transcribed mRNAs possess a cap structure $\left(\mathrm{m}^{7} \mathrm{GpppN}\right.$, in which " $\mathrm{m}$ " represents a methyl group and " $\mathrm{N}$ ", any nucleotide) that is specifically recognized by eukaryotic translation initiation factor 4E (eIF4E; Fig. 4A). eIF4E binds the $5^{\prime}$ cap as a subunit of a complex (termed eIF4F) containing two other proteins, one of two large scaffolding proteins, termed eIF4GI and eIF4GII (encoded by two different genes), and the RNA helicase eIF4A (Gingras et al. 1999b; Hershey and Merrick 2000; Raught et al. 2000b). Following its binding to the $5^{\prime}$ cap, eIF4F is thought to unwind the mRNA 5'-proximal secondary structure to facilitate the binding of the 40S ribosomal subunit in association with several other initiation factors (Gingras et al. 1999b). Unwinding requires another initiation factor, eIF4B (Hershey and Merrick 2000).

Strikingly, several components of the ribosome recruitment machinery as well as ribosomal components are either direct or indirect targets of $\mathrm{mTOR}$. These include eIF4B, eIF4G, and eIF4E, the latter of which is activated by the phosphorylation of its repressors, the 4E$\mathrm{BP}$ proteins. In addition, $\mathrm{S} 6 \mathrm{~K}$ and its targets, the ribosomal protein S6 and elongation factor 2 (eEF2), are also targets of this pathway.

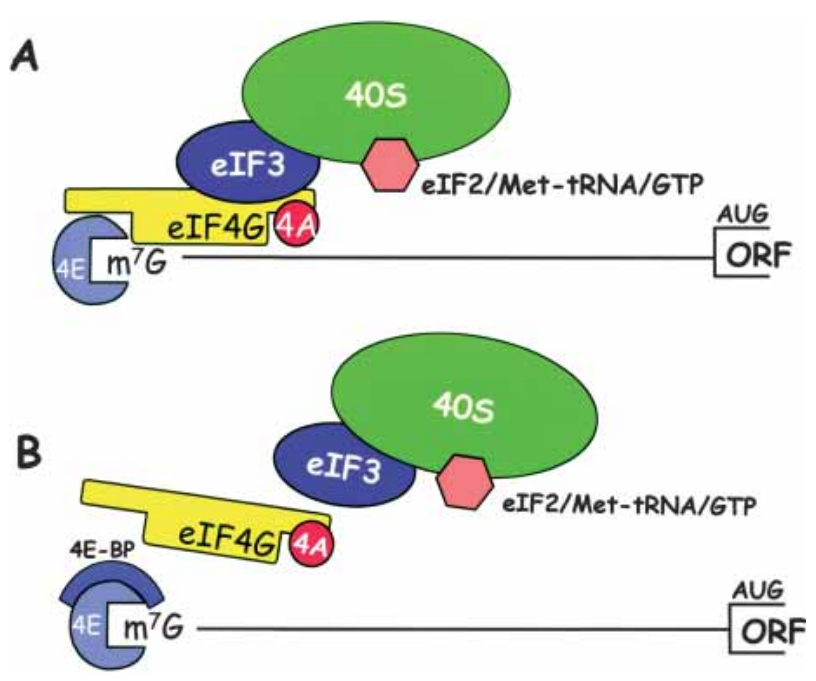

Figure 4. (A) Assembly of the mammalian ribosome initiation complex at the $5^{\prime}$ end of an mRNA. eIF4E, as part of the eIF4F complex, binds the $\mathrm{m}^{7} \mathrm{G}$-cap structure. eIF4G binds eIF3, which, in turn, recruits the $40 \mathrm{~S}$ ribosomal subunit along with its associated ternary complex (eIF2/Met-tRNA/GTP). Not shown are other initiation factors that participate in ribosome recruitment. $(B)$ 4E-BPs binds the dorsal convex surface of eIF4E to prevent its interaction with eIF4G, thereby abrogating ribosome binding. 


\section{$4 E-B P S$}

The interaction between eIF4E and eIF4G is regulated by members of the eIF4E-binding proteins (4E-BPs), a family of translational repressor proteins. The mammalian family consists of three low molecular weight proteins, 4E-BP1, 4E-BP2, and 4E-BP3, encoded by three separate genes, whereas Drosophila expresses only one 4E-BP (4E-BPs; Lin et al. 1994; Pause et al. 1994; Poulin et al. 1998; Bernal and Kimbrell 2000; Miron et al. 2001). The 4E-BPs compete with eIF4G proteins for an overlapping binding site on eIF4E, such that the binding of a 4E-BP or an eIF4G protein is mutually exclusive (Fig. 4B) (Haghighat et al. 1995; Mader et al. 1995; Marcotrigiano et al. 1999).

Whereas hypophosphorylated 4E-BPs bind with high affinity to eIF4E, the hyperphosphorylation of 4E-BPs prevents this interaction. Most of these studies were conducted with 4E-BP1, although this isoform is not the most abundant in all tissues. For example, 4E-BP2 is by far the most abundant isoform in the brain (TsukiyamaKohara et al. 2001). Differences in the kinetics and phosphorylation sites have been observed among the three species (B. Raught and A.C. Gingras, unpubl.). Seven phosphorylation sites have been reported in 4E-BP1 (Thr 37, Thr 46, Ser 65, Thr 70, Ser 83, Ser 101, and Ser 112, numbered according to the human sequence; in rodents, the numbers are lower by one). The first five phosphorylation sites are conserved phylogenetically among all species. However, Ser 101 and Ser 112 exist only in 4E-BP1. There is no general agreement as to the role of the different phosphorylation events in the release of 4E-BP1 from eIF4E. We shall not discuss the literature here, as several recent reviews deal critically with this issue (Gingras et al. 2001b; Harris and Lawrence 2003). However, there is a certain consensus as to the importance of the aggregate phosphorylation of Thr 37, Thr 46, Ser 65, and Thr 70 in the release of 4E-BP1. It is also abundantly clear that phosphorylation, at least in 293 cells, proceeds in an ordered, hierarchical manner (Fig. 5). Immunoprecipitates of mTOR phosphorylate two priming sites in mammalian 4E-BP1 in vitro (Brunn et al. 1997; Burnett et al. 1998; Gingras et al. 2001a). This phosphorylation event is required for subsequent phosphorylation of Thr 70 followed by Ser 65, ultimately resulting in the release of 4E-BP1 from eIF4E (Fig. 5; Gingras et al. 1999a; Heesom and Denton 1999; Mothe-Satney et al. 2000; Gingras et al. 2001a). According to

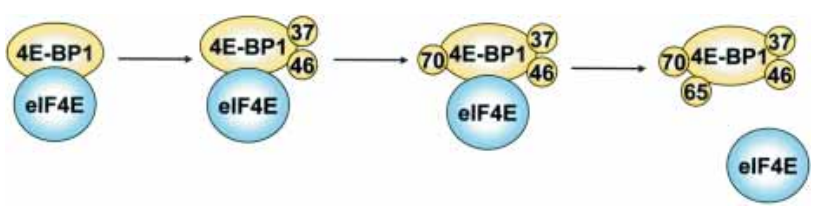

Figure 5. Hierarchical phosphorylation of 4E-BP1 results in its release from eIF4E. Phosphorylation at four sites on 4E-BP1 occurs sequentially. mTOR directly phosphorylates the "priming" sites Thr 37 and Thr 46, but might subsequently also phosphorylate the other sites. several studies, Ser 65 phosphorylation alone appears to be insufficient for the release of 4E-BP1 from eIF4E (Gingras et al. 2001a; Niedzwiecka et al. 2002; Ferguson et al. 2003). However, in one study an amino acid substitution at Ser 65 alone drastically reduced ( 100-fold) the interaction of 4E-BP1 with eIF4E (Karim et al. 2001). However, even in this latter study, the dissociation constant of the complex was low (in the submicromolar range). It is thus conceivable that several phosphorylation events, including Thr 37, Thr 46, Ser 65, and Thr 70, cooperate to promote the release of 4E-BP1 from eIF4E. It is intriguing that a modeled structure of the mammalian 4E-BP1-eIF4E complex based on the structure of the yeast eIF4E-eIF4G complex positions all of the above phosphorylation sites in 4E-BP1 in close proximity to acidic amino acids in eIF4E (Gross et al. 2003). This provides a plausible mechanism to explain how 4E-BP1 dissociates from eIF4E on 4E-BP1 phosphorylation, as negatively charged phosphates would be expected to cause electrostatic repulsion toward acidic amino acids. This was originally suggested to explain the importance of Ser 65 phosphorylation as it is positioned next to Glu 70 in eIF4E (Marcotrigiano et al. 1999).

\section{S6 kinase}

Mammalian cells contain two similar S6 kinase proteins (S6K1 and S6K2) encoded by two different genes (Shima et al. 1998). Both proteins are phosphorylated and all of the phosphorylation sites are conserved between the two proteins. The S6 kinases regulate cell growth in Drosophila and mammals, and are direct targets of TOR. S6K2 was discovered much later than S6K1 (Shima et al. 1998), and therefore, S6K1 has been used for most of the studies on substrate phosphorylation and effects on cell growth. However, a recent report suggests that S6K2 appears to have greater kinase activity in mouse embryo fibroblasts (MEFs) and in several adult tissues, including liver and muscle, because the level of phosphorylation of $\mathrm{S} 6$ is lower in $\mathrm{S} 6 \mathrm{~K} 2^{-/-}$mice relative to $\mathrm{S} 6 \mathrm{~K} 1^{-/-}$mice (Pende et al. 2004).

A large body of evidence implicates S6K1 in the control of cell growth via increased mRNA translation (Montagne et al. 1999; Radimerski et al. 2002). The generally accepted model is that activated S6K promotes the increased translation of 5'TOP (terminal oligopyrimidine tract) mRNAs, which contain a short polypyrimidine stretch (4-14 nucleotides) immediately adjacent to the $5^{\prime}$ cap (Meyuhas and Hornstein 2000). These mRNAs encode exclusively for components of the translation machinery, including all ribosomal proteins, elongation factors, and poly(A)-binding protein (PABP). Critical data supporting the idea that S6K1 is required for 5'TOP mRNA translation include the demonstration that a rapamycin-resistant S6K1 mutant confers rapamycin resistance to the translation of 5'TOP mRNAs (Jefferies et al. 1997; Schwab et al. 1999).

The effect of S6K on mRNA translation is indirect via 
intermediates that are direct downstream effectors of S6K. There are several S6 kinase phosphorylation substrates, the most extensively studied of which is ribosomal protein S6. S6 phosphorylation is generally a good readout for S6K activity, but there are some exceptions (see below). On this basis, and because ribosomal protein S6 phosphorylation correlates well with the translational activation of 5'TOP mRNAs, it was hypothesized that S6 phosphorylation is required to recruit 5'TOP mRNAs to ribosomes (Thomas 2000). However, some recent findings are inconsistent with the idea that ribosomal protein $\mathrm{S} 6$ is the physiologically relevant phosphorylation target or the only one through which the S6 kinases mediate their effects on cell growth and TOP mRNA translation. For example, 5'TOP mRNA translation is activated in response to amino acids and growth factors in $\mathrm{S} 6 \mathrm{~K}^{-1-}$ embryonic stem cells, in which $\mathrm{S} 6$ phosphorylation is undetectable (Tang et al. 2001; Stolovich et al. 2002). Other studies have shown that S6 phosphorylation levels are not decreased in $\mathrm{S} 6 \mathrm{~K}^{-/-}$ mice, suggesting that $\mathrm{S} 6$ phosphorylation is not the only event that mediates the effect of S6Ks on cell growth (Shima et al. 1998). Fingar et al. (2004) showed that the regulation of $\mathrm{G}_{1}$ phase progression by $\mathrm{S} 6 \mathrm{~K} 1$ does not correlate with the phosphorylation of ribosomal protein S6. Moreover, Pende et al. (2004) recently generated embryonic stem cells and MEF cells lacking S6K1 and S6K2 and showed that serum enhances the recruitment of the 5'TOP mRNA, eEF1A, to polysomes to the same extent as in parental cells, and more importantly, that this enhancement is rapamycin sensitive. Therefore, a rapamycin-sensitive target other than S6 must regulate 5'TOP mRNA translation.

As an alternative to S6, eIF4B is a physiologically relevant target of S6K1 that could explain its effect on translation and cell growth. As stated above, eIF4B is required for efficient recruitment of ribosomes to mRNA (Hershey and Merrick 2000). eIF4B is an RNA-binding protein that specifically stimulates the ATPase and RNA helicase activities of eIF4A (Rogers et al. 2002). eIF4B is phosphorylated in response to a variety of extracellular stimuli, such as serum, insulin, and phorbol esters that promote cell growth and proliferation (Duncan and Hershey 1985). Ser 422 is one of the phosphorylation sites in eIF4B. This site is specifically phosphorylated by S6K1/ S6K2 in vitro (Raught et al. 2004). In vivo results are consistent with Ser 422 being a target of S6K1/S6K2 because phosphorylation is sensitive to wortmannin and LY92900, which inhibit PI3K activity (Raught et al. 2004). Moreover, rapamycin-resistant S6Ks confer rapamycin resistance upon Ser 422 phosphorylation in vivo. Consistent with these results, Ser 422 phosphorylation is significantly decreased in $\mathrm{S} 6 \mathrm{~K} 1 / 2$ double knockout cells (M. Livingstone, pers. comm.; M. Pende, pers. comm.). eIF4B may thus be an important mediator of some of the effects of S6Ks on translation and cell growth. Because of its function in assisting eIF4A in unwinding RNA secondary structure, it has been suggested that increased phosphorylation enhances eIF4B activity and the translation of mRNAs containing some degree of secondary structure (Manzella et al. 1991). More recently, Dmitriev et al. (2003) used a ribosome footprinting assay to directly demonstrate that eIF4B is required for ribosome binding on an mRNA containing secondary structure. Moreover, recombinant eIF4B, which is presumably not phosphorylated, could not substitute for native eIF4B in this assay. Also, RNA interference against eIF4B results in selective inhibition of translation of mRNAs having complex structures at their 5'UTR (D. Shabhazian and N. Sonenberg, unpubl.). This selective mechanism to enhance the translation of mRNAs containing secondary structure is very similar to that described for eIF4E (see below).

\section{Regulation of 4E-BP and S6K by dephosphorylation}

Many studies in S. cerevisiae demonstrate that, in addition to the major role that phosphorylation plays in TOR regulation, dephosphorylation by the type $2 \mathrm{~A}$ phosphatases (SIT4, PPH21, and PPH22) also controls this pathway (Di Como and Arndt 1996). In mammalian systems, rapamycin or amino acid deprivation are also reported to activate the phosphatase PP2A, as treatment with the phosphatase inhibitor calyculin prevents 4E-BP1 and S6K1 dephosphorylation (Peterson et al. 1999). Importantly, rapamycin causes dramatic dephosphorylation of all sites in S6K1, including those not phosphorylated by mTOR, arguing in favor of activation of a phosphatase rather than the inhibition of several different kinases. mTOR also phosphorylates PP2A in vitro, consistent with a model in which phosphorylation of PP2A by mTOR prevents the dephosphorylation of 4E-BP1 and S6K1 phosphatase (Peterson et al. 1999). It is possible that $\alpha 4$, the mammalian homolog of TAP42, is also involved in the dephosphorylation of 4E-BP1 and S6K (for review, see Jacinto and Hall 2003).

\section{eIF4G}

eIF4G is a modular scaffolding protein that plays a key role in the assembly of the ribosome initiation complex. As described above, all eukaryotes have two related eIF4G proteins. eIF4Gs consist of three functional and structural domains that are connected by hinge regions. The three domains interact with different initiation factors (Raught et al. 2000b). Both eIF4GI and eIF4GII are phosphoproteins (Tuazon et al. 1989; Raught et al. 2000a), but their phosphorylation appears to be regulated differently (Raught et al. 2000a). Phosphorylation of eIF4GI increases in response to extracellular stimuli, including serum, insulin, and growth factors that promote cell growth (Tuazon et al. 1989; Raught et al. 2000a). Phosphorylation sites have been mapped for both eIF4Gs, but phosphorylation of eIF4GI is much more robust than that of eIF4GII (Raught et al. 2000a). eIF4GI has two clusters of phosphorylation sites, one of which maps to the $\mathrm{N}$-terminal third of the protein that contains Ser 314 (numbering is according to the full-length eIF4GI cDNA clone [Byrd et al. 2002]). Still, the conditions that promote this phosphorylation remain unclear (Raught et 
al. 2000a). A second cluster of serum-stimulated phosphorylation sites maps to the hinge region between the middle and C-terminal domains. These phosphorylation sites comprise Ser 1148, Ser 1188, and Ser 1232, and are sensitive to PI3K and mTOR inhibitors (Raught et al. 2000a). The effect of eIF4GI phosphorylation on its biochemical activity has not been determined, as no evidence for changes in activity or association with other initiation factors has been reported following phosphorylation. However, it is possible that eIF4GI phosphorylation engenders a conformational change in the protein that affects its activity. It is interesting that total phosphorylation of eIF4GII is lower than that of eIF4GI, and phosphorylation is not modulated by serum or mitogens. CaMKI phosphorylates eIF4GII in vitro and in vivo on Ser 1156, which is located in a segment that aligns with the phosphorylated region in eIF4GI (Qin et al. 2003).

In summary, the mTOR signaling pathway regulates the phosphorylation state of three important proteins, including components of the translation initiation machinery (eIF4B, eIF4G) and its critical regulators (4E-BPs), underscoring its importance in controlling translation rates.

\section{Other targets}

There are other reported targets of mTOR that are relevant to translation. The translation elongation factor eEF2 has been studied in some detail. eEF2 is phosphorylated at Thr 56, causing its inactivation. Extracellular stimuli induce the dephosphorylation of eEF2, which is inhibited by rapamycin. These effects are mediated through a specific kinase of eEF2, termed eEF2 kianse. Rapamycin-sensitive phosphorylation of eEF2 kinase occurs on at least three sites, Ser 78, Ser 359, and Ser 366 (Browne and Proud 2004). It is important to determine how the phosphorylation of these residues, both separately and together, controls translation elongation via mTOR. It is also of interest to determine why rapamycin does not affect the translation of IRES-containing mRNAs (Beretta et al. 1996a,b) despite its reported inhibition of elongation.

Another potentially interesting mTOR candidate target is the large subunit (CBP80) of the nuclear cap-binding protein (nCBP; Wilson et al. 2000), which reportedly functions during the initial round of translation of each mRNA (Ishigaki et al. 2001).

\section{mTOR targets involved in transcription}

Consistent with the critical role of mTOR in cell growth via the modulation of protein synthesis in yeast and mammals, it and its yeast homologs strongly stimulate transcription from all genes involved in ribosome biogenesis, transcription of rRNA genes by RNA polymerase I (Pol I), transcription of ribosomal protein genes by RNA polymerase II (Pol II), and transcription of tRNA and 5S genes by RNA polymerase III (Pol III; Mahajan 1994; Zaragoza et al. 1998; Powers and Walter 1999;
Hannan et al. 2003). Recently, several studies identified two mammalian Pol I-specific transcription factors, TIF1A and USB, whose activity is modulated by rapamycin. Mayer et al. (2004) demonstrated that TIF-IA (the homolog of yeast Rrn3, an essential RNA PolI transcription factor [Claypool et al. 2004]) is sufficient to rescue rapamycin-mediated inhibition of rDNA transcription. Also, in yeast the TOR pathway regulates Rrn3p-dependent recruitment of yeast Pol I to its promoter (Claypool et al. 2004). Thus, at least some of the downstream effectors of $\mathrm{mTOR}$ that regulate rDNA transcription appear to be conserved in evolution. However, Hannan and colleagues could not demonstrate that TIF-IA is regulated by mTOR (Hannan et al. 2003). Instead, they demonstrated that the rDNA transcription factor UBF (upstream binding factor) is responsible for the stimulation of rDNA transcription by mTOR, which is dependent on S6K activity. Treatment with rapamycin inhibits the phosphorylation of UBF in its C-terminal region, and this phosphorylation is required for the activity of UBF. Interestingly, UBF does not appear to be a direct substrate for S6K1, implying the existence of a novel kinase upstream of UBF.

\section{mTOR translational control, cell growth, and proliferation}

As introduced above, under most circumstances, the rate-limiting step in mammalian translation initiation is the binding of the ribosome to mRNA. Strikingly, almost all of the factors involved in recruiting the ribosome, including eIF4E, eIF4B, and eIF4G, are phosphoproteins whose phosphorylation states are directly proportional to the translation and growth rates of the cell. In addition, the repressor proteins, 4E-BPs, are similarly phosphorylated under the same circumstances. Thus, increased phosphorylation of these factors in response to numerous extracellular stimuli correlates with increased translation of a subset of mRNAs (see below) and accelerated growth and proliferation (for review, see Raught et al. 2000b; Gingras et al. 2001a). It is striking that the mTOR pathway mediates the phosphorylation of all of these factors, except for eIF4E. How does phosphorylation of these factors affect translation, and consequently, cell growth? An attractive hypothesis is based on the finding that eIF4E is limiting in the cell (Duncan et al. 1987), which might underlie the finding that ribosome binding is the rate-limiting step during translation initiation (Mathews et al. 2000). Because eIF4E is part of the eIF4F complex, it stands to reason that an increase in any of the components of eIF4F would enhance translation initiation rates. Inasmuch as the eIF4F complex functions to recognize the mRNA $5^{\prime}$ cap and unwind the mRNA 5' secondary structure, it has been postulated that the translation of mRNAs containing extensive secondary structure would be preferably stimulated by increased eIF4E activity (Sonenberg 1993). eIF4E overexpression in cells enabled efficient translation of a reporter mRNA in which more secondary structure had been inserted in the mRNA 5' UTR (Koromilas et al. 
1992). Subsequently, several groups identified mRNAs whose translation was preferentially stimulated in eIF4E-overexpressing NIH-3T3 cells as well as other cell lines. These mRNAs include, among others, ODC (ornithine decarboxylase), FGF (fibroblast growth factor), and VEGF (vascular endothelial growth factor). Two common features of these mRNAs are (1) a relatively long and structured 5' UTR, and (2) most importantly, their protein products function in controlling cell growth and proliferation. Hence, the translational activation of these mRNAs is expected to promote cell growth and proliferation. ODC has been studied in some detail, as it is a model par excellence for studying translational control by eIF4E. It contains a G/C-rich 5' UTR of $~ 300 \mathrm{nt}$ and is not well translated in vivo or in vitro. In response to insulin stimulation, which activates eIF4E, its translation increases by $\sim 30$-fold (Manzella et al. 1991). Consistent with these findings, the translation of ODC in eIF4E-overexpressing NIH-3T3 cells is also increased by 30-fold (Shantz and Pegg 1994). Experimentally induced elevation in the levels of other components of eIF4F and eIF4B would be expected to elicit similar effects.

Several studies have directly measured and documented the effects of eIF4E on cell growth and proliferation. One study showed that eIF4E overexpression increases cell size, and that eIF4E and S6K cooperate downstream of TOR to control cell size (Fingar et al. 2002). A subsequent study (Fingar et al. 2004) reported that eIF4E and S6K also promote cell cycle progression. This is not surprising, because cell growth and cell division are generally tightly coupled in yeast as well as in mammals, under most circumstances. These results are also consistent with the earlier finding that eIF4E overexpression in NIH-3T3 cells promotes malignant transformation (see below), which requires an increase in both growth and proliferation. Thus, the S6K and eIF4E/4E-BP pathways promote proliferation by coupling cell growth with cell cycle progression.

\section{mTOR and cancer}

The signaling pathways that regulate mTOR activity are frequently activated in human cancers. For instance, loss-of-function mutations of the tumor suppressor PTEN in human cancers occur with a frequency nearly that of the tumor suppressor p53 (Cantley and Neel 1999; Simpson and Parsons 2001). In addition, the genes encoding the catalytic subunit of PI3K and Akt are amplified in subsets of human cancers (Vivanco and Sawyers 2002). Ras, which binds and activates the catalytic subunit of $\mathrm{PI} 3 \mathrm{~K}$, is activated in $\sim 30 \%$ of epithelial tumors (Downward 2003). These lesions in signaling pathways that regulate mTOR activity obviously affect other downstream effectors of these pathways. However, the observation that patients with mutations in TSC1 and TSC2 develop hamartomas (Jones et al. 1999) and the finding that Rheb expression and activity are elevated in cancer cell lines (Im et al. 2002) provide more direct evidence that the activation of mTOR contributes to the genesis of cancer. Consistent with these data, the rapa- mycin derivative CCI-779 inhibits the hyperproliferation of PTEN-deficient cells (Neshat et al. 2001). Also, the administration of CCI-779 to PTEN heterozygous mice, which develop multiple neoplasia, attenuates tumor development (Podsypanina et al. 2001). Moreover, targeting of activated Akt to the mouse prostate induces prostate intraepithelial neoplasia (PIN), which is reversed following administration of the rapamycin derivative RAD001 (Majumder et al. 2004). Consequently, two important and related questions have emerged, namely, how mTOR contributes to the genesis of cancer and whether such occurs through the up-regulated translation of growth-associated mRNAs. One mechanism by which mTOR can contribute to cancer development is through its effect on cell cycle progression in conjunction with its possible anti-apoptotic activity. There is strong evidence that, like yeast TOR, MTOR is required for cell cycle progression, and inhibition of mTOR activity by rapamycin arrests cells in the $G_{1}$ phase of the cell cycle (for reviews, see Abraham and Wiederrecht 1996; Jacinto and Hall 2003). Expression of a rapamycin-resistant mutant of mTOR alleviates the effect of rapamycin on cell cycle progression, and there is evidence that the effect of rapamycin on cell cycle progression occurs via the inhibition of the downstream effectors of mTOR, S6K, and eIF4E (Fingar et al. 2004). This effect of mTOR on cell cycle progression is mediated, at least in part, by the increased translation of mRNAs encoding positive regulators of cell cycle progression, such as cyclin D1 and c-Myc, and by decreased translation of negative regulators thereof, such as the cyclin-dependent kinase inhibitor, p27 (Gera et al. 2004). In addition to the effect on cell cycle progression, under certain circumstances, the inhibition of mTOR activity by rapamycin accelerates apoptosis (Shi et al. 1995; Huang et al. 2001; Thimmaiah et al. 2003), and eIF4E inhibits apoptosis in certain instances (Polunovsky et al. 1996; Herbert et al. 2000; Tan et al. 2000). However, the exact mechanism by which eIF4E inhibits apoptosis is not clear.

It has been known for some time that overexpression of eIF4E or eIF4G in immortalized rodent cells causes malignant transformation (Lazaris-Karatzas et al. 1990; Fukuchi-Shimogori et al. 1997). Furthermore, eIF4E transforms rat embryo fibroblasts in concert with an immortalizing gene such as E1A or v-myc, thus demonstrating that eIF4E acts as an oncogene in this established two-oncogene transformation assay (LazarisKaratzas and Sonenberg 1992). Ectopic expression of eIF4E in immortalized human mammary epithelial cells also causes transformation, as judged by the ability of cells to form foci on a cell monolayer and to grow in soft agar (Avdulov et al. 2004). Consistent with the oncogenic potential of eIF4E and eIF4G, there is ample evidence that they and other translation initiation factors (such as eIF4A and several subunits of eIF3) are overexpressed in human tumors (for reviews, see De Benedetti and Harris 1999; Hershey and Miyamoto 2000; Ruggero and Pandolfi 2003). Recently, the oncogenic activity of eIF4E was also demonstrated using transgenic mice overexpressing this protein (Ruggero et al. 2004). Interest- 
ingly, the mice developed tumors late in life (14-16 mo), but when coexpressed with Myc, the tumors appeared much earlier (2-3 mo), consistent with the earlier in vitro results mentioned above (Lazaris-Karatzas and Sonenberg 1992). These observations strongly suggest that the components of the eIF4F complex are the most critical downstream effectors of $\mathrm{mTOR}$ in the genesis of cancer. The levels and the activity of these components are normally tightly regulated and, as described above, eIF4F and possibly eIF4G are rate-limiting components of the ribosome recruiting machinery and are limiting in the cell. As described above, these components form the eIF4E complex, whose prime function is to recognize the mRNA 5' cap structure and unwind the 5' secondary structure of the mRNA. Therefore, when tight regulation of eIF4E or eIF4G is compromised, the translation of mRNAs containing such structures would be constitutively enhanced and lead to the production of proteins that would increase cell growth and proliferation. Recent evidence supports the notion that the tumorigenic effects of upstream components of mTOR are mediated by its downstream effectors (Wendel et al. 2004). This research demonstrates that Akt confers resistance to apoptosis by anti-cancer drugs such as doxorubicin using an E $\mu-M y c$ model of B-cell lymphoma (Adams et al. 1985). This effect is reversed by rapamycin. These data substantiate previous results showing that PTEN-deficient prostate cancer cells are resistant to doxorubicin, and that resistance is alleviated when cells are cotreated with rapamycin (Grunwald et al. 2002). Therefore, Wendel et al. (2004) postulated that a downstream target of mTOR mediates anti-apoptotic drug resistance, and they could restore drug resistance by expression of eIF4E. These results corroborate earlier findings that eIF4E has anti-apoptotic activity in growth factor-restricted fibroblasts expressing deregulated Myc (Polunovsky et al. 1996). However, unless the anti-apoptotic activity of eIF4E is separate from its effect on protein synthesis as previously suggested (Herbert et al. 2000), it is unclear whether this is the major mechanism by which Akt exerts its anti-apoptotic function, as it has been shown that Akt inhibits apoptosis in the absence of de novo protein synthesis (Gottlob et al. 2001; Rathmell et al. 2003). In addition, eIF4E mediates mTOR-dependent cell cycle progression (Fingar et al. 2004), and activated 4E-BP1 attenuates the progression through the $G_{1}$ phase of the cell cycle and blocks transformation by c-Myc (Lynch et al. 2004). Thus, it is unlikely that the only tumorigenic function of eIF4E is to inhibit apoptosis.

A strong link between mRNA translation and the genesis of cancer was recently demonstrated by Rajasekhar et al. (2003), who showed that the expression of constitutively active Ras and Akt in primary glial progenitor cells causes glioblastoma. Surprisingly, they found a dramatic effect on the recruitment of a subclass of mRNAs to polysomes, but very modest effects on the levels of these mRNAs at early times after the induction of Akt and Ras expression. Interestingly, many of the mRNAs recruited to the ribosomes encode proteins that are implicated in cancer. Some of these proteins are transcrip- tion factors, which, in turn, activate the transcription of genes involved in these processes (Rajasekhar et al. 2003). Thus, a reasonable interpretation of these data is that Akt and Ras activate the ribosome recruiting machinery via mTOR to enhance translation of key factors that control cell proliferation.

The observation described above strongly supports a role for the ability of mTOR to regulate mRNA translation in the genesis of cancer. However, recent results suggest that the ability of mTOR to regulate the transcription (that might be indirect) of certain genes is also associated with the development of neoplasia. The development of PIN mediated by Akt is associated with the elevation of mRNA levels of a number of genes whose expression is decreased following the administration of the rapamycin analog, RAD001, which also reverses the development of PIN (Majumder et al. 2004). The ability of mTOR to affect the expression of these genes was attributed to its effect on the transcription factor HIF-1 $\alpha$ (Semenza 2003; Majumder et al. 2004). On the basis of the aforementioned discussion, it is not surprising that rapamycin inhibits tumor growth and is currently in phase I-III clinical trails (for reviews, see Mita et al. 2003; Sawyers 2003; Bjornsti and Houghton 2004; Houghton and Huang 2004).

\section{mTOR function in synaptic plasticity, memory, and learning}

The creation and maintenance of long-term memory requires new mRNA and protein synthesis (Kandel 2001), which are not required for short-term memory. Synaptic plasticity is the process by which the strength of synaptic connections changes in response to experience, and it is thought to be critical for the learning process. A leading model for the cellular plasticity underlying learning is long-term potentiation (LTP), in which the pairing of input stimulation and postsynaptic depolarization leads to long-term increases in the strength of the synaptic connection between input and output. Whereas late LTP requires transcription and translation, early LTP, similar to short-term memory, does not. LTP can be recorded in several places in the brain, but has been examined most extensively in the hippocampus, in which spatial memory is recorded.

Translation factors, ribosomes, and mRNAs are found localized in dendrites at the base of dendritic spines under post-synaptic sites. Interestingly, a large fraction of the mRNAs are kept in an inactive state in RNA granules, which are not translationally competent, most likely because eIF4E, eIF4G, and tRNAs are absent (Krichevsky and Kosik 2001). Local release of mRNAs and ribosomes from granules may link mRNA localization to translation and synaptic plasticity, as local translation in dendrites has been demonstrated following stimulation by BDNF (Brain-Derived Neurotrophic Factor) or neurotrophin 3 (NT-3; Kang and Schuman 1996). Strikingly, protein synthesis is independent of the nucleus and cell body, as it also can occur in isolated dendrites (Kang and Schuman 1996). 
The TOR signaling pathway was first implicated in learning and memory by showing that rapamycin inhibits long-term facilitation in Aplysia (Casadio et al. 1999). 5-Hydroxytryptamine (5-HT), the facilitating neurotransmitter in Aplysia, increases the rate of translation in Aplysia neurons (Yanow et al. 1998), activates S6K (Khan et al. 2001), and increases levels of CPEB (cytoplasmic polyadenylation element binding protein), which promotes the polyadenylation and translation of a subset of mRNAs through the rapamycin-sensitive system (Si et al. 2003). Rapamycin also inhibits late LTP, which is induced by BDNF or high-frequency electrical stimulation in hippocampal slices (Tang et al. 2002; Cammalleri et al. 2003). Consistent with a requirement for a rapamycin-sensitive signaling pathway in hippocampal synaptic plasticity, mTOR and its downstream targets, 4E-BPs and S6K, are present at post-synaptic sites (Tang et al. 2002). Other work has demonstrated that the mTOR pathway is activated in response to BDNF as S6K1 and 4E-BP1 become phosphorylated (Takei et al. 2001). Interestingly, Rheb, which plays a critical role in signaling to mTOR, is very abundant in the brain and was first cloned via a differential screen of mRNAs that are transcribed in neurons upon seizure induction (Yamagata et al. 1994)

In a rather new twist to the translation-LTP connection in the brain, a recent study demonstrated that phosphorylation of 4E-BP1 and S6 in neurons is also regulated by the ERK pathway, which plays a major role in LTP (Kelleher et al. 2004). Thus, it appears that the ERK signaling pathway plays a critical role in translational control in hippocampal neurons, and that the ERK and mTOR pathways cooperate to regulate protein synthesis-an absolute requisite for LTP.

\section{Concluding remarks and perspectives}

The mTOR pathway is emerging as a critical player in the etiology of cancer and metabolic diseases, including diabetes and obesity. The recent breathtaking advances in the understanding of the upstream and downstream targets of mTOR provide rational explanations for the origins and progression of these diseases. For example, insulin is a major upstream effector of mTOR that increases protein synthesis as part of the modulation of anabolic processes in response to glucose. Thus, deficiencies in mTOR signaling might play a role in the development of glucose- and insulin-resistant type II diabetes (Pende et al. 2000). As discussed above, a link between the mTOR pathway and cancer is also clearly evident, as most of the upstream and downstream components of mTOR are directly implicated in cancer initiation and progression. The enhanced understanding of the mTOR signaling pathway should lead to the design of drugs to treat diabetes and cancer. The success of rapamycin in clinical trials for cancer, restenosis in heart valves (Marks 2003), and arthritis (Forre et al. 2000) highlights the multitude of diseases whose origins stem from aberrant proliferation and that are linked to mTOR. Other drugs that act on other compo- nents of the pathway are also sought. Studies are in progress to develop drugs that inhibit upstream mTOR effectors such as Akt/PKB or downstream targets such as eIF4E.

Several important details related to the regulation of mTOR activity remain unresolved. In particular, the mechanism by which Rheb activates mTOR is still elusive, and future studies will be likely directed toward resolving this link. In addition, as discussed earlier, there needs to be clarification on the interplay between the regulation of mTOR activity by growth factors and by nutrients. Another important and unresolved question concerns the identity of the downstream target(s) of S6K, which activates the translation of TOP mRNAs to stimulate cell growth. As described above, eIF4B could be a candidate (Raught et al. 2004), although other as yet undiscovered proteins could also play a role (e.g., see Fingar et al. 2004).

An important avenue for future studies is the understanding of the cross-talk between the PI3K-Akt/PKBmTOR signaling pathway and the signaling pathway leading to the activation of ERK. It is clear that both pathways cooperate to effect many cellular functions. These interactions have critical consequences for the control of cell growth, memory, and learning. These two signaling pathways activate key components of the translational machinery involved in recruiting ribosomes to mRNA. The ERK pathway is responsible for phosphorylating eIF4E (Waskiewicz et al. 1997; Pyronnet et al. 1999; Radimerski et al. 2002), a modification that is thought to increase its activity; whereas, as described above, the mTOR pathway phosphorylates 4E-BPs, which, in turn, stimulate eIF4E activity and enhance ribosome recruitment. Recent experiments show that the ERK and mTOR pathways cooperate to stimulate translation and induce glioblastomas in a mouse model (Rajasekhar et al. 2003). As both pathways become activated in neurons in response to experience, they likely cooperate to promote new protein synthesis required for learning and memory.

\section{Acknowledgments}

We thank Davide Ruggero and So Young Kim for helpful comments on this review. Work in the authors' laboratories was supported by grants from the NIH (N.H. and N.S.) and the National institute of Canada, Canadian Institute of Health Research (CIHR), and Howard Hughes Medical Institute (HHMI; N.S.). N.S. is a CIHR Distinguished Scientist and an HHMI International Scholar.

\section{References}

Abraham, R.T. and Wiederrecht, G.J. 1996. Immunopharmacology of rapamycin. Annu. Rev. Immunol. 14: 483-510.

Adams, J.M., Harris, A.W., Pinkert, C.A., Corcoran, L.M., Alexander, W.S., Cory, S., Palmiter, R.D., and Brinster, R.L. 1985. The c-myc oncogene driven by immunoglobulin enhancers induces lymphoid malignancy in transgenic mice. Nature 318: 533-538. 
Andrade, M.A. and Bork, P. 1995. HEAT repeats in the Huntington's disease protein. Nat. Genet. 11: 115-116.

Avdulov, S., Li, S., Van, M., Burrichter, D., Peterson, M., Perlman, D.M., Manivel, J.C., Sonenberg, N., Yee, D., Bitterman, P.B., et al. 2004. Activation of translation complex eIF4F is essential for the genesis and maintenance of the malignant phenotype in human mammary epithelial cells. Cancer Cell 5: 553-563.

Beretta, L., Gingras, A.-C., Svitkin, Y.V., Hall, M.N., and Sonenberg, N. 1996a. Rapamycin blocks the phosphorylation of 4E-BP1 and inhibits cap-dependent initiation of translation. EMBO J. 15: 658-664.

Beretta, L., Svitkin, Y.V., and Sonenberg, N. 1996b. Rapamycin stimulates viral protein synthesis and augments the shutoff of host protein synthesis upon picornavirus infection. J. Virol. 70: 8993-8996.

Bernal, A. and Kimbrell, D.A. 2000. Drosophila Thor participates in host immune defense and connects a translational regulator with innate immunity. Proc. Natl. Acad. Sci. 97: 6019-6024.

Beugnet, A., Wang, X., and Proud, C.G. 2003. Target of rapamycin (TOR)-signaling and RAIP motifs play distinct roles in the mammalian TOR-dependent phosphorylation of initiation factor 4E-binding protein 1. J. Biol. Chem. 278: 4071740722.

Bjornsti, M.A. and Houghton, P.J. 2004. The TOR pathway: A target for cancer therapy. Nat. Rev. Cancer 4: 335-348.

Bosotti, R., Isacchi, A., and Sonnhammer, E.L. 2000. FAT: A novel domain in PIK-related kinases. Trends Biochem. Sci. 25: 225-227.

Brazil, D.P. and Hemmings, B.A. 2001. Ten years of protein kinase B signalling: A hard Akt to follow. Trends Biochem. Sci. 26: 657-664.

Brown, E.J., Albers, M.W., Shin, T.B., Ichikawa, K., Keith, C.T., Lane, W.S., and Schreiber, S.L. 1994. A mammalian protein targeted by $\mathrm{G}_{1}$-arresting rapamycin-receptor complex. $\mathrm{Na}$ ture 369: 756-758.

Brown, E.J., Beal, P.A., Keith, C.T., Chen, J., Shin, T.B., and Schreiber, S.L. 1995. Control of p70 s6 kinase by kinase activity of FRAP in vivo. Nature 377: 441-446.

Browne, G.J. and Proud, C.G. 2004. A novel mTOR-regulated phosphorylation site in elongation factor 2 kinase modulates the activity of the kinase and its binding to calmodulin. Mol. Cell. Biol. 24: 2986-2997.

Brunn, G.J., Williams, J., Sabers, C., Wiederrecht, G., Lawrence Jr., J.C., and Abraham, R.T. 1996. Direct inhibition of the signaling functions of the mammalian target of rapamycin by the phosphoinositide 3-kinase inhibitors, wortmannin and LY294002. EMBO J. 15: 5256-5267.

Brunn, G.J., Hudson, C.C., Sekulic, A., Williams, J.M., Hosoi, H., Houghton, P.J., Lawrence Jr., J.C., and Abraham, R.T. 1997. Phosphorylation of the translational repressor PHAS-I by the mammalian target of rapamycin. Science 277:99101.

Burnett, P.E., Barrow, R.K., Cohen, N.A., Snyder, S.H., and Sabatini, D.M. 1998. RAFT1 phosphorylation of the translational regulators p70 S6 kinase and 4E-BP1. Proc. Nat1. Acad. Sci. 95: 1432-1437.

Byrd, M.P., Zamora, M., and Lloyd, R.E. 2002. Generation of multiple isoforms of eukaryotic translation initiation factor 4GI by use of alternate translation initiation codons. Mol. Cell. Biol. 22: 4499-4511.

Cammalleri, M., Lutjens, R., Berton, F., King, A.R., Simpson, C., Francesconi, W., and Sanna, P.P. 2003. Time-restricted role for dendritic activation of the mTOR-p70S6K pathway in the induction of late-phase long-term potentiation in the
CA1. Proc. Natl. Acad. Sci. 100: 14368-14373.

Cantley, L.C. and Neel, B.G. 1999. New insights into tumor suppression: PTEN suppresses tumor formation by restraining the phosphoinositide 3-kinase/AKT pathway. Proc. Nat1. Acad. Sci. 96: 4240-4245.

Casadio, A., Martin, K.C., Giustetto, M., Zhu, H.,Chen, M., Bartsch, D., Bailey, C.H., and Kandel, E.R. 1999. A transient, neuron-wide form of CREB-mediated long-term facilitation can be stabilized at specific synapses by local protein synthesis. Cell 99: 221-237.

Castro, A.F., Rebhun, J.F., Clark, G.J., and Quilliam, L.A. 2003. Rheb binds tuberous sclerosis complex 2 (TSC2) and promotes S6 kinase activation in a rapamycin- and farnesylation-dependent manner. J. Biol. Chem. 278: 32493-32496.

Cheadle, J.P., Reeve, M.P., Sampson, J.R., and Kwiatkowski, D.J. 2000. Molecular genetic advances in tuberous sclerosis. Hum. Genet. 107: 97-114.

Cheatham, B., Vlahos, C.J., Cheatham, L., Wang, L., Blenis, J., and Kahn, C.R. 1994. Phosphatidylinositol 3-kinase activation is required for insulin stimulation of pp70 S6 kinase, DNA synthesis, and glucose transporter translocation. Mol. Cell. Biol. 14: 4902-4911.

Chen, E.J. and Kaiser, C.A. 2003. LST8 negatively regulates amino acid biosynthesis as a component of the TOR pathway. J. Cell. Biol. 161: 333-347.

Chen, J., Zheng, X.F., Brown, E.J., and Schreiber, S.L. 1995. Identification of an 11-kDa FKBP12-rapamycin-binding domain within the 289-kDa FKBP12-rapamycin-associated protein and characterization of a critical serine residue. Proc. Natl. Acad. Sci. 92: 4947-4951.

Cheng, S.W., Fryer, L.G., Carling, D., and Shepherd, P.R. 2004. Thr2446 is a novel mammalian target of rapamycin (mTOR) phosphorylation site regulated by nutrient status. I. Biol. Chem. 279: 15719-15722.

Chiu, M.I., Katz, H., and Berlin, V. 1994. RAPT1, a mammalian homolog of yeast Tor, interacts with the FKBP12/rapamycin complex. Proc. Nat1. Acad. Sci. 91: 12574-12578.

Choi, J., Chen, J., Schreiber, S.L., and Clardy, J. 1996. Structure of the FKBP12-rapamycin complex interacting with the binding domain of human FRAP. Science 273: 239-242.

Choi, K.M., McMahon, L.P., and Lawrence Jr., J.C. 2003. Two motifs in the translational repressor PHAS-I required for efficient phosphorylation by mammalian target of rapamycin and for recognition by raptor. J. Biol. Chem. 278: 1966719673.

Chung, J., Grammer, T.C., Lemon, K.P., Kazlauskas, A., and Blenis, J. 1994. PDGF- and insulin-dependent pp70S6k activation mediated by phosphatidylinositol-3-OH kinase. $\mathrm{Na}$ ture 370: 71-75.

Claypool, J.A., French, S.L., Johzuka, K., Eliason, K., Vu, L., Dodd, J.A., Beyer, A.L., and Nomura, M. 2004. Tor pathway regulates Rrn3p-dependent recruitment of yeast RNA polymerase I to the promoter but does not participate in alteration of the number of active genes. Mol. Biol. Cell 15: $946-$ 956.

Crespo, J.L. and Hall, M.N. 2002. Elucidating TOR signaling and rapamycin action: Lessons from Saccharomyces cerevisiae. Microbiol. Mol. Biol. Rev. 66: 579-591.

Dan, H.C., Sun, M., Yang, L., Feldman, R.I., Sui, X.M., Ou, C.C., Nellist, M., Yeung, R.S., Halley, D.J., Nicosia, S.V., et al. 2002. Phosphatidylinositol 3-kinase/Akt pathway regulates tuberous sclerosis tumor suppressor complex by phosphorylation of tuberin. J. Biol. Chem. 277: 35364-35370.

De Benedetti, A. and Harris, A.L. 1999. eIF4E expression in tumors: Its possible role in progression of malignancies. Int. J. Biochem. Cell. Biol. 31: 59-72. 
Dennis, P.B., Jaeschke, A., Saitoh, M., Fowler, B., Kozma, S.C., and Thomas, G. 2001. Mammalian TOR: A homeostatic ATP sensor. Science 294: 1102-1105.

Di Como, C.J. and Arndt, K.T. 1996. Nutrients, via the Tor proteins, stimulate the association of Tap42 with type $2 \mathrm{~A}$ phosphatases. Genes \& Dev. 10: 1904-1916.

Dmitriev, S.E., Terenin, I.M., Dunaevsky, Y.E., Merrick, W.C., and Shatsky, I.N. 2003. Assembly of 48 S translation initiation complexes from purified components with mRNAs that have some base pairing within their $5^{\prime}$ untranslated regions. Mol. Cell. Biol. 23: 8925-8933.

Downward, J. 2003. Targeting RAS signalling pathways in cancer therapy. Nat. Rev. Cancer. 3: 11-22.

Dufner, A., Andjelkovic, M., Burgering, B.M., Hemmings, B.A., and Thomas, G. 1999. Protein kinase B localization and activation differentially affect $\mathrm{S} 6$ kinase 1 activity and eukaryotic translation initiation factor 4E-binding protein 1 phosphorylation. Mol. Cell. Biol. 19: 4525-4534.

Duncan, R. and Hershey, J.W. 1985. Regulation of initiation factors during translational repression caused by serum depletion. Covalent modification. J. Biol. Chem. 260: 54935497.

Duncan, R., Milburn, S.C., and Hershey, J.W. 1987. Regulated phosphorylation and low abundance of HeLa cell initiation factor eIF-4F suggest a role in translational control. Heat shock effects on eIF-4F. J. Biol. Chem. 262: 380-388.

The European Chromosome 16 Tuberous Sclerosis Consortium. 1993. Identification and characterization of the tuberous sclerosis gene on chromosome 16. Cell 75: 1305-1315.

Fang, Y., Vilella-Bach, M., Bachmann, R., Flanigan, A., and Chen, J. 2001. Phosphatidic acid-mediated mitogenic activation of mTOR signaling. Science 294: 1942-1945.

Fang, Y., Park, I.H., Wu, A.L., Du, G., Huang, P., Frohman, M.A., Walker, S.J., Brown, H.A. and Chen, J. 2003. PLD1 regulates $\mathrm{mTOR}$ signaling and mediates $\mathrm{Cdc} 42$ activation of S6K1. Curr. Biol. 13: 2037-2044.

Ferguson, G., Mothe-Satney, I., and Lawrence Jr., J.C. 2003. Ser64 and Ser-111 in PHAS-I are dispensable for insulin-stimulated dissociation from eIF4E. J. Biol. Chem. 278: 4745947465.

Fingar, D.C., Salama, S., Tsou, C., Harlow, E., and Blenis, J. 2002. Mammalian cell size is controlled by $\mathrm{mTOR}$ and its downstream targets S6K1 and 4EBP1/eIF4E. Genes \& Dev. 16: $1472-1487$.

Fingar, D.C., Richardson, C.J., Tee, A.R., Cheatham, L., Tsou, C., and Blenis, J. 2004. mTOR controls cell cycle progression through its cell growth effectors S6K1 and 4E-BP1/eukaryotic translation initiation factor 4E. Mol. Cell. Biol. 24: 200216.

Forre, O., Haugen, M., and Hassfeld, W.G. 2000. New treatment possibilities in rheumatoid arthritis. Scand. I. Rheumatol. 29: $73-84$.

Fukuchi-Shimogori, T., Ishii, I., Kashiwagi, K., Mashiba, H., Ekimoto, H., and Igarashi, K. 1997. Malignant transformation by overproduction of translation initiation factor eIF4G. Cancer Res. 57: 5041-5044.

Gao, X. and Pan, D. 2001. TSC1 and TSC2 tumor suppressors antagonize insulin signaling in cell growth. Genes \& Dev. 15: $1383-1392$.

Gao, X., Zhang, Y., Arrazola, P., Hino, O., Kobayashi, T., Yeung, R.S., Ru, B., and Pan, D. 2002. Tsc tumour suppressor proteins antagonize amino-acid-TOR signalling. Nat. Cell. Biol. 4: 699-704.

Garami, A., Zwartkruis, F.J., Nobukuni, T., Joaquin, M., Roccio, M., Stocker, H., Kozma, S.C., Hafen, E., Bos, J.L., and Thomas, G. 2003. Insulin activation of Rheb, a mediator of
mTOR/S6K/4E-BP signaling, is inhibited by TSC1 and 2 . Mol. Cell 11: 1457-1466.

Gera, J.F., Mellinghoff, I.K., Shi, Y., Rettig, M.B., Tran, C., Hsu, J.H., Sawyers, C.L., and Lichtenstein, A.K. 2004. AKT activity determines sensitivity to mammalian target of rapamycin (mTOR) inhibitors by regulating cyclin D1 and c-myc expression. J. Biol. Chem. 279: 2737-2746.

Gingras, A.C., Kennedy, S.G., O'Leary, M.A., Sonenberg, N., and Hay, N. 1998. 4E-BP1, a repressor of mRNA translation, is phosphorylated and inactivated by the Akt $(\mathrm{PKB})$ signaling pathway. Genes \& Dev. 12: 502-513.

Gingras, A.-C., Gygi, S.P., Raught, B., Polakiewicz, R.D., Abraham, R.T., Hoekstra, M.F., Aebersold, R., and Sonenberg, N. 1999a. Regulation of 4E-BP1 phosphorylation: A novel twostep mechanism. Genes \& Dev. 13: 1422-1437.

Gingras, A.-C., Raught, B., and Sonenberg, N. 1999b. eIF4 initiation factors: Effectors of mRNA recruitment to ribosomes and regulators of translation. Annu. Rev. Biochem. 68: 913963.

Gingras, A.-C., Raught, B., Gygi, S.P., Niedzwiecka, A., Miron, M., Burley, S.K., Polakiewicz, R.D., Wyslouch-Cieszynska, A., Aebersold, R., and Sonenberg. N. 2001a. Hierarchical phosphorylation of the translation inhibitor 4E-BP1. Genes \& Dev. 15: 2852-2864.

Gingras, A.-C., Raught, B., and Sonenberg, N. 2001b. Regulation of translation initiation by FRAP/mTOR. Genes \& Dev. 15: 807-826.

Goncharova, E.A., Goncharov, D.A., Eszterhas, A., Hunter, D.S., Glassberg, M.K., Yeung, R.S., Walker, C.L., Noonan, D., Kwiatkowski, D.J., Chou, M.M., et al. 2002. Tuberin regulates p70 S6 kinase activation and ribosomal protein S6 phosphorylation. A role for the TSC2 tumor suppressor gene in pulmonary lymphangioleiomyomatosis (LAM). I. Biol. Chem. 277: 30958-30967.

Gottlob, K., Majewski, N., Kennedy, S., Kandel, E., Robey, R.B., and Hay, N. 2001. Inhibition of early apoptotic events by Akt/PKB is dependent on the first committed step of glycolysis and mitochondrial hexokinase. Genes \& Dev. 15: 1406-1418.

Gross, J.D., Moerke, N.J., von der Haar, T., Lugovskoy, A.A., Sachs, A.B., McCarthy, J.E., and Wagner, G. 2003. Ribosome loading onto the mRNA cap is driven by conformational coupling between eIF4G and eIF4E. Cell 115: 739-750.

Grunwald, V., DeGraffenried, L., Russel, D., Friedrichs, W.E., Ray, R.B., and Hidalgo, M. 2002. Inhibitors of mTOR reverse doxorubicin resistance conferred by PTEN status in prostate cancer cells. Cancer Res. 62: 6141-6145.

Haddad, L.A., Smith, N., Bowser, M., Niida, Y., Murthy, V., Gonzalez-Agosti, C., and Ramesh.,V. 2002. The TSC1 tumor suppressor hamartin interacts with neurofilament-L and possibly functions as a novel integrator of the neuronal cytoskeleton. I. Biol. Chem. 277: 44180-44186.

Haghighat, A., Mader, S., Pause, A., and Sonenberg, N. 1995. Repression of cap-dependent translation by 4E-binding protein 1: Competition with p220 for binding to eukaryotic initiation factor-4E. EMBO I. 14: 5701-5709.

Hall, M.N. 1996. The TOR signalling pathway and growth control in yeast. Biochem. Soc. Trans. 24: 234-239.

Hannan, K.M., Brandenburger, Y., Jenkins, A., Sharkey, K., Cavanaugh, A., Rothblum, L., Moss, T., Poortinga, G., McArthur, G.A., Pearson, R.B., et al. 2003. mTOR-dependent regulation of ribosomal gene transcription requires S6K1 and is mediated by phosphorylation of the carboxyterminal activation domain of the nucleolar transcription factor UBF. Mol. Cell. Biol. 23: 8862-8877.

Hara, K., Maruki, Y., Long, X., Yoshino, K., Oshiro, N., Hidayat, 
S., Tokunaga, C., Avruch, J., and Yonezawa, K. 2002. Raptor, a binding partner of target of rapamycin (TOR), mediates TOR action. Cell 110: 177-189.

Hardie, D.G., Carling, D., and Carlson, M. 1998. The AMPactivated/SNF1 protein kinase subfamily: Metabolic sensors of the eukaryotic cell? Annu. Rev. Biochem. 67: 821-855.

Harris, T.E. and Lawrence Jr., J.C. 2003. TOR signaling. Sci STKE 2003: re15.

Heesom, K.J. and Denton, R.M. 1999. Dissociation of the eukaryotic initiation factor-4E/4E-BP1 complex involves phosphorylation of $4 \mathrm{E}-\mathrm{BP} 1$ by an mTOR-associated kinase. Febs Lett. 457: 489-493.

Helliwell, S.B., Wagner, P., Kunz, J., Deuter-Reinhard, M., Henriquez, R., and Hall, M.N. 1994. TOR1 and TOR2 are structurally and functionally similar but not identical phosphatidylinositol kinase homologues in yeast. Mol. Biol. Cell 5: 105-118.

Herbert, T.P., Fahraeus, R., Prescott, A., Lane, D.P., and Proud, C.G. 2000. Rapid induction of apoptosis mediated by peptides that bind initiation factor eIF4E. Curr. Biol. 10: 793796.

Hershey, J.W.B. and Merrick, W.C. 2000. Pathway and mechanism of initiation of protein synthesis. In Translational control of gene expression (ed. M.B. Mathews), pp. 33-88. Cold Spring Harbor Laboratory Press, Cold Spring Harbor, N.Y.

Hershey, J.W.B. and Miyamoto, S. 2000. Translational control and cancer. In Translational control of gene expression (ed. M.B. Mathews), pp. 637-654. Cold Spring Harbor Laboratory Press, Cold Spring Harbor, N.Y.

Houghton, P.J. and Huang, S. 2004. mTOR as a target for cancer therapy. Curr. Top. Microbiol. Immunol. 279: 339-359.

Huang, S., Liu, L.N., Hosoi, H., Dilling, M.B., Shikata, T., and Houghton, P.J. 2001. p53/p21(CIP1) cooperate in enforcing rapamycin-induced G(1) arrest and determine the cellular response to rapamycin. Cancer Res. 61: 3373-3381.

Im, E., von Lintig, F.C., Chen, J., Zhuang, S., Qui, W., Chowdhury, S., Worley, P.F., Boss, G.R., and Pilz, R.B. 2002. Rheb is in a high activation state and inhibits B-Raf kinase in mammalian cells. Oncogene 21: 6356-6365.

Inoki, K., Li, Y., Zhu, T., Wu, J., and Guan, K.L. 2002. TSC2 is phosphorylated and inhibited by Akt and suppresses mTOR signalling. Nat. Cell. Biol. 4: 648-657.

Inoki, K., Li, Y., Xu, T., and Guan, K.L. 2003a. Rheb GTPase is a direct target of TSC2 GAP activity and regulates mTOR signaling. Genes \& Dev. 17: 1829-1834.

Inoki, K., Zhu, T., and Guan, K.L. 2003b. TSC2 mediates cellular energy response to control cell growth and survival. Cell 115: 577-590.

Ishigaki, Y., Li, X., Serin, G., and Maquat, L.E. 2001. Evidence for a pioneer round of mRNA translation: mRNAs subject to nonsense-mediated decay in mammalian cells are bound by CBP80 and CBP20. Cell 106: 607-617.

Jacinto, E. and Hall, M.N. 2003. Tor signalling in bugs, brain and brawn. Nat. Rev. Mol. Cell. Biol. 4: 117-126.

Jaeschke, A., Hartkamp, J., Saitoh, M., Roworth, W., Nobukuni, T., Hodges, A., Sampson, J., Thomas, G., and Lamb, R. 2002. Tuberous sclerosis complex tumor suppressor-mediated S6 kinase inhibition by phosphatidylinositide-3-OH kinase is mTOR independent. J. Cell. Biol. 159: 217-224.

Jefferies, H.B., Fumagalli, S., Dennis, P.B., Reinhard, C., Pearson, R.B., and Thomas, G. 1997. Rapamycin suppresses 5'TOP mRNA translation through inhibition of p7056k. EMBO J. 16: 3693-3704.

Jones, A.C., Shyamsundar, M.M., Thomas, M.W., Maynard, J., Idziaszczyk, S., Tomkins, S., Sampson, J.R., and Cheadle, J.P. 1999. Comprehensive mutation analysis of TSC1 and TSC2- and phenotypic correlations in 150 families with tuberous sclerosis. Am. J. Hum. Genet. 64: 1305-1315.

Kandel, E.R. 2001. The molecular biology of memory storage: A dialogue between genes and synapses. Science 294: 10301038.

Kandel, E.S. and Hay, N. 1999. The regulation and activities of the multifunctional serine/threonine kinase Akt/PKB. Exp. Cell. Res. 253: 210-229.

Kang, H. and Schuman, E.M. 1996. A requirement for local protein synthesis in neurotrophin-induced hippocampal synaptic plasticity. Science 273: 1402-1406.

Karim, M.M., Hughes, J.M.X., Warwicker, J., Scheper, G.C., Proud, C.G., and McCarthy, J.E.G. 2001. A quantitative molecular model for modulation of mammalian translation by the eIF4E-binding protein 1. I. Biol. Chem. 276: 2075020757.

Kelleher III, R.J., Govindarajan, A., Jung, H.Y., Kang, H., and Tonegawa, S. 2004. Translational control by MAPK signaling in long-term synaptic plasticity and memory. Cell 116: 467-479.

Kemp, B.E., Mitchelhill, K.I., Stapleton, D., Michell, B.J., Chen, Z.P., and Witters, L.A. 1999. Dealing with energy demand: The AMP-activated protein kinase. Trends Biochem. Sci. 24: 22-25.

Khan, A., Pepio, A.M., and Sossin, W.S. 2001. Serotonin activates $\mathrm{S} 6$ kinase in a rapamycin-sensitive manner in Aplysia synaptosomes. J. Neurosci. 21: 382-391.

Kim, D.H., Sarbassov, D.D., Ali, S.M., King, J.E., Latek, R.R., Erdjument-Bromage, H., Tempst, P., and Sabatini, D.M. 2002. mTOR interacts with raptor to form a nutrient-sensitive complex that signals to the cell growth machinery. Cell 110: $163-175$.

Kim, D.H., Sarbassov, D.D., Ali, S.M., Latek, R.R., Guntur, K.V., Erdjument-Bromage, H., Tempst, P., and Sabatini, D.M. 2003. GßL, a positive regulator of the rapamycin-sensitive pathway required for the nutrient-sensitive interaction between raptor and mTOR. Mol. Cell 11: 895-904.

Kimura, N., Tokunaga, C., Dalal, S., Richardson, C., Yoshino, K., Hara, K., Kemp, B.E., Witters, L.A., Mimura, O., and Yonezawa, K. 2003. A possible linkage between AMP-activated protein kinase (AMPK) and mammalian target of rapamycin (mTOR) signalling pathway. Genes Cells 8: 65-79.

Koromilas, A.E., Lazaris-Karatzas, A., and Sonenberg, N. 1992. mRNAs containing extensive secondary structure in their $5^{\prime}$ non-coding region translate efficiently in cells overexpressing initiation factor eIF-4E. EMBO J. 11: 4153-4158.

Krichevsky, A.M. and Kosik, K.S. 2001. Neuronal RNA granules: A link between RNA localization and stimulation-dependent translation. Neuron 32: 683-696.

Kunz, J., Henriquez, R., Schneider, U., Deuter-Reinhard, M., Movva, N.R., and Hall, M.N. 1993. Target of rapamycin in yeast, TOR2, is an essential phosphatidylinositol kinase homolog required for G1 progression. Cell 73: 585-596.

Kwiatkowski, D.J., Zhang, H., Bandura, J.L., Heiberger, K.M., Glogauer, M., el-Hashemite, N., and Onda, H. 2002. A mouse model of TSC1 reveals sex-dependent lethality from liver hemangiomas, and up-regulation of p70S6 kinase activity in Tsc1 null cells. Hum. Mol. Genet. 11: 525-534.

Lamb, R.F., Roy, C., Diefenbach, T.J., Vinters, H.V., Johnson, M.W., Jay, D.G., and Hall, A. 2000. The TSC1 tumour suppressor hamartin regulates cell adhesion through ERM proteins and the GTPase Rho. Nat. Cell. Biol. 2: 281-287.

Lazaris-Karatzas, A. and Sonenberg, N. 1992. The mRNA 5' cap-binding protein, eIF-4E, cooperates with v-myc or E1A in the transformation of primary rodent fibroblasts. Mol. Cell. Biol. 12: 1234-1238. 
Lazaris-Karatzas, A., Montine, K.S., and Sonenberg, N. 1990. Malignant transformation by a eukaryotic initiation factor subunit that binds to mRNA 5' cap. Nature 345: 544-547.

Li, Y., Inoki, K., Yeung, R., and Guan, K.L. 2002. Regulation of TSC2 by 14-3-3 binding. J. Biol. Chem. 277: 44593-44596.

Lin, T.A., Kong, X., Haystead, T.A., Pause, A., Belsham, G., Sonenberg, N., and Lawrence Jr., J.C. 1994. PHAS-I as a link between mitogen-activated protein kinase and translation initiation. Science 266: 653-656.

Liu, M.Y., Cai, S., Espejo, A., Bedford, M.T., and Walker, C.L. 2002. 14-3-3 interacts with the tumor suppressor tuberin at Akt phosphorylation site(s). Cancer Res. 62: 6475-6480.

Lizcano, J.M., Alrubaie, S., Kieloch, A., Deak, M., Leevers, S.J., and Alessi, D.R. 2003. Insulin-induced Drosophila S6 kinase activation requires phosphoinositide 3-kinase and protein kinase B. Biochem. J. 374: 297-306.

Loewith, R., Jacinto, E., Wullschleger, S., Lorberg, A., Crespo, J.L., Bonenfant, D., Oppliger, W., Jenoe, P., and Hall, M.N. 2002. Two TOR complexes, only one of which is rapamycin sensitive, have distinct roles in cell growth control. Mol. Cell 10: 457-468.

Long, X., Spycher, C., Han, Z.S., Rose, A.M., Muller, F., and Avruch, J. 2002. TOR deficiency in C. elegans causes developmental arrest and intestinal atrophy by inhibition of mRNA translation. Curr. Biol. 12: 1448-1461.

Lynch, M., Fitzgerald, C., Johnston, K.A., Wang, S., and Schmidt, E.V. 2004. Activated eIF4E-binding protein slows G1 progression and blocks transformation by c-myc without inhibiting cell growth. J. Biol. Chem. 279: 3327-3339.

Mach, K.E., Furge, K.A., and Albright, C.F. 2000. Loss of Rhb1, a Rheb-related GTPase in fission yeast, causes growth arrest with a terminal phenotype similar to that caused by nitrogen starvation. Genetics 155: 611-622.

Mader, S., Lee, H., Pause, A., and Sonenberg, N. 1995. The translation initiation factor eIF-4E binds to a common motif shared by the translation factor eIF- $4 \gamma$ and the translational repressors 4E-binding proteins. Mol. Cell. Biol. 15: 49904997.

Mahajan, P.B. 1994. Modulation of transcription of rRNA genes by rapamycin. Int. J. Immunopharmacol. 16: 711-721.

Majumder, P.K., Febbo, P.G., Bikoff, R., Berger, R., Xue, Q., McMahon, L.M., Manola, J., Brugarolas, J., McDonnell, T.J., Golub, T.R., et al. 2004. mTOR inhibition reverses Akt-dependent prostate intraepithelial neoplasia through regulation of apoptotic and HIF-1-dependent pathways. Nat. Med. 10: 594-601.

Manning, B.D., Tee, A.R., Logsdon, M.N., Blenis, J., and Cantley, L.C. 2002. Identification of the tuberous sclerosis complex-2 tumor suppressor gene product tuberin as a target of the phosphoinositide 3-kinase/akt pathway. Mol. Cell 10: $151-162$.

Manzella, J.M., Rychlik, W., Rhoads, R.E., Hershey, J.W., and Blackshear, P.J. 1991. Insulin induction of ornithine decarboxylase. Importance of mRNA secondary structure and phosphorylation of eucaryotic initiation factors eIF-4B and eIF-4E. J. Biol. Chem. 266: 2383-2389.

Marcotrigiano, J., Gingras, A.-C., Sonenberg, N., and Burley, S.K. 1999. Cap-dependent translation initiation in eukaryotes is regulated by a molecular mimic of eIF4G. Mol. Cell 3: 707-716.

Marks, A.R. 2003. Sirolimus for the prevention of in-stent restenosis in a coronary artery. N. Engl. I. Med. 349: 13071309.

Mathews, M.B., Sonenberg, N., and Hershey, J.W.B. 2000. Origins and principles of translational control. In Translational control of gene expression (ed. M.B. Mathews), pp. 1-31.
Cold Spring Harbor Laboratory Press, Cold Spring Harbor, N.Y.

Matsumoto, S., Bandyopadhyay, A., Kwiatkowski, D.J., Maitra, U., and Matsumoto, T. 2002. Role of the Tsc1-Tsc2 complex in signaling and transport across the cell membrane in the fission yeast Schizosaccharomyces pombe. Genetics 161: 1053-1063.

Mayer, C., Zhao, J., Yuan, X., and Grummt, I. 2004. mTORdependent activation of the transcription factor TIF-IA links rRNA synthesis to nutrient availability. Genes \& Dev. 18: $423-434$.

Mendez, R., Myers Jr., M.G., White, M.F., and Rhoads, R.E. 1996. Stimulation of protein synthesis, eukaryotic translation initiation factor 4E phosphorylation, and PHAS-I phosphorylation by insulin requires insulin receptor substrate 1 and phosphatidylinositol 3-kinase. Mol. Cell. Biol. 16: 28572864.

Meyuhas, O. and Hornstein, E. 2000. Translational control of TOP mRNAs. In Translational control of gene expression (ed. M.B. Mathews), pp. 671-694. Cold Spring Harbor Laboratory Press, Cold Spring Harbor, N.Y.

Miron, M., Verdu, J., Lachance, P.E., Birnbaum, M.J., Lasko, P.F., and Sonenberg, N. 2001. The translational inhibitor 4E$\mathrm{BP}$ is an effector of $\mathrm{PI}(3) \mathrm{K} /$ Akt signalling and cell growth in Drosophila. Nat. Cell. Biol. 3: 596-601.

Miron, M., Lasko, P., and Sonenberg, N. 2003. Signaling from Akt to FRAP/TOR targets both 4E-BP and S6K in Drosophila melanogaster. Mol. Cell. Biol. 23: 9117-9126.

Mita, M.M., Mita, A., and Rowinsky, E.K. 2003. The molecular target of rapamycin (mTOR) as a therapeutic target against cancer. Cancer Biol. Ther. 2: S169-S177.

Montagne, J., Stewart, M.J., Stocker, H., Hafen, E., Kozma, S.C., and Thomas, G. 1999. Drosophila S6 kinase: A regulator of cell size. Science 285: 2126-2129.

Mothe-Satney, I., Yang, D., Fadden, P., Haystead, T.A., and Lawrence Jr, J.C. 2000. Multiple mechanisms control phosphorylation of PHAS-I in five $(\mathrm{S} / \mathrm{T}) \mathrm{P}$ sites that govern translational repression. Mol. Cell. Biol. 20: 3558-3567.

Nave, B.T., Ouwens, M., Withers, D.J., Alessi, D.R., and Shepherd, P.R. 1999. Mammalian target of rapamycin is a direct target for protein kinase B: Identification of a convergence point for opposing effects of insulin and amino-acid deficiency on protein translation. Biochem. J. 344 Pt 2: 427-431.

Nellist, M., Goedbloed, M.A., de Winter, C., Verhaaf, B., Jankie, A., Reuser, A.J., van den Ouweland, A.M., van der Sluijs, P., and Halley, D.J. 2002. Identification and characterization of

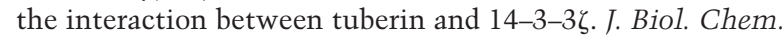
277: 39417-39424.

Neshat, M.S., Mellinghoff, I.K., Tran, C., Stiles, B., Thomas, G., Petersen, R., Frost, P., Gibbons, J.J., Wu, H., and Sawyers, C.L. 2001. Enhanced sensitivity of PTEN-deficient tumors to inhibition of FRAP/mTOR. Proc. Natl. Acad. Sci. 98: 10314-10319.

Niedzwiecka, A., Marcotrigiano, J., Stepinski, J., JankowskaAnyszka, M., Wyslouch-Cieszynska, A., Dadlez, M., Gingras, A.C., Mak, P., Darzynkiewicz, E., Sonenberg, N., et al. 2002. Biophysical studies of eIF4E cap-binding protein: Recognition of mRNA 5' cap structure and synthetic fragments of eIF4G and 4E-BP1 proteins. J. Mol. Biol. 319: 615-635.

Nojima, H., Tokunaga, C., Eguchi, S., Oshiro, N., Hidayat, S., Yoshino, K., Hara, K., Tanaka, N., Avruch, J., and Yonezawa, K. 2003. The mammalian target of rapamycin (mTOR) partner, raptor, binds the mTOR substrates p70 S6 kinase and 4E-BP1 through their TOR signaling (TOS) motif. J. Biol. Chem. 278: 15461-15464.

Oldham, S., Montagne, J., Radimerski, T., Thomas, G., and 
Hafen, E. 2000. Genetic and biochemical characterization of dTOR, the Drosophila homolog of the target of rapamycin. Genes \& Dev. 14: 2689-2694.

Oshiro, N., Yoshino, K., Hidayat, S., Tokunaga, C., Hara, K., Eguchi, S., Avruch, J., and Yonezawa, K. 2004. Dissociation of raptor from mTOR is a mechanism of rapamycin-induced inhibition of mTOR function. Genes Cells 9: 359-366.

Patel, P.H., Thapar, N., Guo, L., Martinez, M., Maris, J., Gau, C.L., Lengyel, J.A., and Tamanoi, F. 2003. Drosophila Rheb GTPase is required for cell cycle progression and cell growth. J. Cell. Sci. 116: 3601-3610.

Pause, A., Belsham, G.J., Gingras, A.-C., Donzé, O., Lin, T.A., Lawrence Jr., J.C., and Sonenberg, N. 1994. Insulin-dependent stimulation of protein synthesis by phosphorylation of a regulator of $5^{\prime}$-cap function. Nature 371: 762-767.

Pende, M., Kozma, S.C., Jaquet, M., Oorschot, V., Burcelin, R., Le Marchand-Brustel, Y., Klumperman, J., Thorens, B., and Thomas, G. 2000. Hypoinsulinaemia, glucose intolerance and diminished $\beta$-cell size in S6K1-deficient mice. Nature 408: 994-997.

Pende, M., Um, S.H., Mieulet, V., Sticker, M., Goss, V.L., Mestan, J., Mueller, M., Fumagalli, S., Kozma, S.C., and Thomas, G. 2004. S6 $\mathrm{K}^{-/-} / \mathrm{S} 6 \mathrm{~K} 2^{-/-}$Mice exhibit perinatal lethality and rapamycin-sensitive 5 '-terminal oligopyrimidine mRNA translation and reveal a mitogen-activated protein kinase-dependent S6 kinase pathway. Mol. Cell. Biol. 24: 3112-3124.

Peng, X.D., Xu, P.Z., Chen, M.L., Hahn-Windgassen, A., Skeen, J., Jacobs, J., Sundararajan, D., Chen, W.S., Crawford, S.E., Coleman, K.G., et al. 2003. Dwarfism, impaired skin development, skeletal muscle atrophy, delayed bone development, and impeded adipogenesis in mice lacking Akt1 and Akt2. Genes \& Dev. 17: 1352-1365.

Peterson, R.T., Desai, B.N., Hardwick, J.S., and Schreiber, S.L. 1999. Protein phosphatase $2 \mathrm{~A}$ interacts with the $70-\mathrm{kDa}$ S6 kinase and is activated by inhibition of FKBP12-rapamycin associated protein. Proc. Natl. Acad. Sci. 96: 4438-4442.

Peterson, R.T., Beal, P.A., Comb, M.J., and Schreiber, S.L. 2000. FKBP12-rapamycin-associated protein (FRAP) autophosphorylates at serine 2481 under translationally repressive conditions. J. Biol. Chem. 275: 7416-7423.

Podsypanina, K., Lee, R.T., Politis, C., Hennessy, I., Crane, A., Puc, J., Neshat, M., Wang, H., Yang, L., Gibbons, J., et al. 2001. An inhibitor of mTOR reduces neoplasia and normalizes p70/S6 kinase activity in Pten ${ }^{+/-}$mice. Proc. Natl. Acad. Sci. 98: 10320-10325.

Polunovsky, V.A., Rosenwald, I.B., Tan, A., White, J., Chiang, L., Sonenberg, N., and Bitterman, P.B. 1996. Translational control of programmed cell death: Eukaryotic translation initiation factor 4E blocks apoptosis in growth-factor-restricted fibroblasts with physiologically expressed or deregulated Myc. Mol. Cell. Biol. 16: 6573-6581.

Potter, C.J., Huang, H., and Xu, T. 2001. Drosophila Tsc1 functions with Tsc2 to antagonize insulin signaling in regulating cell growth, cell proliferation, and organ size. Cell 105: $357-$ 368.

Potter, C.J., Pedraza, L.G., and Xu, T. 2002. Akt regulates growth by directly phosphorylating Tsc2. Nat. Cell. Biol. 4: 658-665.

Poulin, F., Gingras, A.-C., Olsen, H., Chevalier, S., and Sonenberg, N. 1998. 4E-BP3, a new member of the eukaryotic initiation factor 4E-binding protein family. J. Biol. Chem. 273: 14002-14007.

Powers, T. and Walter, P. 1999. Regulation of ribosome biogenesis by the rapamycin-sensitive TOR-signaling pathway in Saccharomyces cerevisiae. Mol. Biol. Cell 10: 987-1000.
Pyronnet, S., Imataka, H., Gingras, A.-C., Fukunaga, R., Hunter, T., and Sonenberg, N. 1999. Human eukaryotic translation initiation factor 4G (eIF4G) recruits MNK1 to phosphorylate eIF4E. EMBO J. 18: 270-279.

Qin, H., Raught, B., Sonenberg, N., Goldstein, E.G., and Edelman, A.M. 2003. Phosphorylation screening identifies translational initiation factor 4GII as an intracellular target of $\mathrm{Ca}^{2+} /$ calmodulin-dependent protein kinase I. J. Biol. Chem. 278: 48570-48579.

Radimerski, T., Montagne, J., Rintelen, F., Stocker, H., van der Kaay, J., Downes, C.P., Hafen, E., and Thomas, G. 2002. dS6K-regulated cell growth is $\mathrm{dPKB} / \mathrm{dPI} / 3 \mid \mathrm{K}$-independent, but requires dPDK1. Nat. Cell. Biol. 4: 251-255.

Rajasekhar, V.K., Viale, A., Socci, N.D., Wiedmann, M., Hu, X., and Holland, E.C. 2003. Oncogenic Ras and Akt signaling contribute to glioblastoma formation by differential recruitment of existing mRNAs to polysomes. Mol. Cell 12: 889901.

Rathmell, J.C., Fox, C.J., Plas, D.R., Hammerman, P.S., Cinalli, R.M., and Thompson, C.B. 2003. Akt-directed glucose metabolism can prevent Bax conformation change and promote growth factor-independent survival. Mol. Cell. Biol. 23: 7315-7328.

Raught, B., Gingras, A.-C., Gygi, S.P., Imataka, H., Morino, S., Gradi, A., Aebersold, R., and Sonenberg, N. 2000a. Serumstimulated, rapamycin-sensitive phosphorylation sites in the eukaryotic translation initiation factor 4GI. EMBO $\mathrm{I}$. 19: 434-444.

Raught, B., Gingras, A.-C., and Sonenberg, N. 2000b. Regulation of ribosomal recruitment in eukaryotes. In Translational control of gene expression (ed. M.B. Mathews), pp. 245-294. Cold Spring Harbor Laboratory Press, Cold Spring Harbor, N.Y.

Raught, B., Peiretti, F., Gingras, A.C., Livingstone, M., Shahbazian, D., Mayeur, G.L., Polakiewicz, R.D., Sonenberg, N., and Hershey, J.W. 2004. Phosphorylation of eucaryotic translation initiation factor 4B Ser422 is modulated by S6 kinases. EMBO J. 23: 1761-1769.

Reynolds IV, T.H., Bodine, S.C., and Lawrence Jr., J.C. 2002. Control of Ser2448 phosphorylation in the mammalian target of rapamycin by insulin and skeletal muscle load. J. Biol. Chem. 277: 17657-17662.

Rogers Jr., G.W., Komar, A.A., and Merrick, W.C. 2002. eIF4A: The godfather of the DEAD box helicases. Prog. Nucleic Acid Res. Mol. Biol. 72: 307-331.

Ruggero, D. and Pandolfi, P.P. 2003. Does the ribosome translate cancer? Nat. Rev. Cancer 3: 179-192.

Ruggero, D., Montanaro, L., Ma, L., Xu, W., Londei, P.C.-C., and Pandolfi, P.P. 2004. Role of the translation factor eIF4E in tumorigenesis and c-MYC cooperative lymphomagenesis. Nat. Med. 10: 484-486.

Sabatini, D.M., Erdjument-Bromage, H., Lui, M., Tempst, P., and Snyder, S.H. 1994. RAFT1: A mammalian protein that binds to FKBP12 in a rapamycin-dependent fashion and is homologous to yeast TORs. Cell 78: 35-43.

Sabers, C.J., Martin, M.M., Brunn, G.J., Williams, J.M., Dumont, F.J., Wiederrecht, G., and Abraham, R.T. 1995. Isolation of a protein target of the FKBP12-rapamycin complex in mammalian cells. J. Biol. Chem. 270: 815-822.

Sarbassov, D.D., Ali, S.M., Kim, D.-H., Guertin, D.A., Latek, R.R., Erdjument-Bromage, H., Tempst, P., and Sabatini, D.M. 2004. Rictor, a novel binding partner of mTOR, defines a rapamycin-insensitive and Raptor-independent pathway that regulates the cytoskeleton. Curr. Biol. 14: 1-20.

Saucedo, L.J., Gao, X., Chiarelli, D.A., Li, L., Pan, D., and Edgar, B.A. 2003. Rheb promotes cell growth as a component of the 
insulin/TOR signalling network. Nat. Cell. Biol. 5: 566-571. Sawyers, C.L. 2003. Will mTOR inhibitors make it as cancer drugs? Cancer Cell 4: 343-348.

Scanga, S.E., Ruel, L., Binari, R.C., Snow, B., Stambolic, V., Bouchard, D., Peters, M., Calvieri, B., Mak, T.W., Woodgett, J.R., et al. 2000. The conserved PI3'K/PTEN/Akt signaling pathway regulates both cell size and survival in Drosophila. Oncogene 19: 3971-3977.

Schalm, S.S. and Blenis, J. 2002. Identification of a conserved motif required for mTOR signaling. Curr. Biol. 12: 632-639.

Schalm, S.S., Fingar, D.C., Sabatini, D.M., and Blenis, J. 2003. TOS motif-mediated raptor binding regulates 4E-BP1 multisite phosphorylation and function. Curr. Biol. 13: 797-806.

Scheid, M.P. and Woodgett, J.R. 2001. PKB/AKT: Functional insights from genetic models. Nat. Rev. Mol. Cell. Biol. 2: 760-768.

Schmelzle, T. and Hall, M.N. 2000. TOR, a central controller of cell growth. Cell 103: 253-262.

Schmidt, A., Kunz, J., and Hall, M.N. 1996. TOR2 is required for organization of the actin cytoskeleton in yeast. Proc. Natl. Acad. Sci. 93: 13780-13785.

Schwab, M.S., Kim, S.H., Terada, N., Edfjäll, C., Kozma, S.C., Thomas, G., and Maller, J.L. 1999. p70(S6K) controls selective mRNA translation during oocyte maturation and early embryogenesis in Xenopus laevis. Mol. Cell. Biol. 19: 24852494.

Scott, P.H., Brunn, G.J., Kohn, A.D., Roth, R.A., and Lawrence Jr., J.C. 1998. Evidence of insulin-stimulated phosphorylation and activation of the mammalian target of rapamycin mediated by a protein kinase B signaling pathway. Proc. Nat1. Acad. Sci. 95: 7772-7777.

Sekulic, A., Hudson, C.C., Homme, J.L., Yin, P., Otterness, D.M., Karnitz, L.M., and Abraham, R.T. 2000. A direct linkage between the phosphoinositide 3-kinase-AKT signaling pathway and the mammalian target of rapamycin in mitogen-stimulated and transformed cells. Cancer Res. 60: 35043513.

Semenza, G.L. 2003. Targeting HIF-1 for cancer therapy. Nat. Rev. Cancer 3: 721-732.

Shantz, L.M. and Pegg, A.E. 1994. Overproduction of ornithine decarboxylase caused by relief of translational repression is associated with neoplastic transformation. Cancer Res. 54: 2313-2316.

Sharma, P.M., Egawa, K., Huang, Y., Martin, J.L., Huvar, I., Boss, G.R., and Olefsky, J.M. 1998. Inhibition of phosphatidylinositol 3-kinase activity by adenovirus-mediated gene transfer and its effect on insulin action. J. Biol. Chem. 273: 1852818537.

Shi, Y., Frankel, A., Radvanyi, L.G., Penn, L.Z., Miller, R.G., and Mills, G.B. 1995. Rapamycin enhances apoptosis and increases sensitivity to cisplatin in vitro. Cancer Res. 55: 1982-1988.

Shima, H., Pende, M., Chen, Y., Fumagalli, S., Thomas, G., and Kozma, S.C. 1998. Disruption of the p70S6k/p85S6k gene reveals a small mouse phenotype and a new functional S6 kinase. EMBO J. 17: 6649-6659.

Shumway, S.D., Li, Y., and Xiong, Y. 2003. 14-3-3 $\beta$ binds to and negatively regulates the tuberous sclerosis complex 2 (TSC2) tumor suppressor gene product, tuberin. J. Biol. Chem. 278: 2089-2092.

Si, K., Giustetto, M., Etkin, A., Hsu, R., Janisiewicz, A.M., Miniaci, M.C., Kim, J.H., Zhu, H., and Kandel, E.R. 2003. A neuronal isoform of CPEB regulates local protein synthesis and stabilizes synapse-specific long-term facilitation in aplysia. Cell 115: 893-904.

Simpson, L. and Parsons, R. 2001. PTEN: Life as a tumor sup- pressor. Exp. Cell. Res. 264: 29-41.

Sonenberg, N. 1993. Remarks on the mechanism of ribosome binding to eukaryotic mRNAs. Gene Expr. 3: 317-323.

Stocker, H., Radimerski, T., Schindelholz, B., Wittwer, F., Belawat, P., Daram, P., Breuer, S., Thomas, G., and Hafen, E. 2003. Rheb is an essential regulator of $S 6 \mathrm{~K}$ in controlling cell growth in Drosophila. Nat. Cell. Biol. 5: 559-565.

Stolovich, M., Tang, H., Hornstein, E., Levy, G., Cohen, R., Bae, S.S., Birnbaum, M.J., and Meyuhas, O. 2002. Transduction of growth or mitogenic signals into translational activation of TOP mRNAs is fully reliant on the phosphatidylinositol 3-kinase-mediated pathway but requires neither S6K1 nor rpS6 phosphorylation. Mol. Cell. Biol. 22: 8101-8113.

Tabancay Jr., A.P., Gau, C.L., Machado, I.M., Uhlmann, E.J., Gutmann, D.H., Guo, L., and Tamanoi, F. 2003. Identification of dominant negative mutants of Rheb GTPase and their use to implicate the involvement of human Rheb in the activation of p70S6K. J. Biol. Chem. 278: 39921-39930.

Takahashi, T., Hara, K., Inoue, H., Kawa, Y., Tokunaga, C., Hidayat, S., Yoshino, K., Kuroda, Y., and Yonezawa, K. 2000. Carboxyl-terminal region conserved among phosphoinositide-kinase-related kinases is indispensable for mTOR function in vivo and in vitro. Genes Cells 5: 765-775.

Takei, N., Kawamura, M., Hara, K., Yonezawa, K., and Nawa, H. 2001. Brain-derived neurotrophic factor enhances neuronal translation by activating multiple initiation processes: Comparison with the effects of insulin. I. Biol. Chem. 276: 42818-42825.

Tan, A., Bitterman, P., Sonenberg, N., Peterson, M., and Polunovsky, V. 2000. Inhibition of Myc-dependent apoptosis by eukaryotic translation initiation factor $4 \mathrm{E}$ requires cyclin D1. Oncogene 19: 1437-1447.

Tang, H., Hornstein, E., Stolovich, M., Levy, G., Livingstone, M., Templeton, D., Avruch, J., and Meyuhas, O. 2001. Amino acid-induced translation of TOP mRNAs is fully dependent on phosphatidylinositol 3-kinase-mediated signaling, is partially inhibited by rapamycin, and is independent of S6K1 and rpS6 phosphorylation. Mol. Cell. Biol. 21: 86718683.

Tang, S.J., Reis, G., Kang, H., Gingras, A.C., Sonenberg, N., and Schuman, E.M. 2002. A rapamycin-sensitive signaling pathway contributes to long-term synaptic plasticity in the hippocampus. Proc. Natl. Acad. Sci. 99: 467-472.

Tapon, N., Ito, N., Dickson, B.J., Treisman, J.E., and Hariharan, I.K. 2001. The Drosophila tuberous sclerosis complex gene homologs restrict cell growth and cell proliferation. Cell 105: 345-355.

Tee, A.R., Fingar, D.C., Manning, B.D., Kwiatkowski, D.J., Cantley, L.C., and Blenis, J. 2002. Tuberous sclerosis complex-1 and -2 gene products function together to inhibit mammalian target of rapamycin (mTOR)-mediated downstream signaling. Proc. Natl. Acad. Sci. 99: 13571-13576.

Tee, A.R., Anjum, R., and Blenis, J. 2003a. Inactivation of the tuberous sclerosis complex- 1 and -2 gene products occurs by phosphoinositide 3-kinase/Akt-dependent and -independent phosphorylation of tuberin. J. Biol Chem. 278: 37288-37296.

Tee, A.R., Manning, B.D., Roux, P.P., Cantley, L.C., and Blenis, J. 2003b. Tuberous sclerosis complex gene products, Tuberin and Hamartin, control mTOR signaling by acting as a GTPase-activating protein complex toward Rheb. Curr. Biol. 13: 1259-1268.

Thimmaiah, K.N., Easton, J., Huang, S., Veverka, K.A., Germain, G.S., Harwood, F.C., and Houghton, P.J. 2003. Insulinlike growth factor I-mediated protection from rapamycininduced apoptosis is independent of Ras-Erk1-Erk2 and phosphatidylinositol 3 '-kinase-Akt signaling pathways. Cancer 
Res. 63: 364-374.

Thomas, G. 2000. An encore for ribosome biosynthesis in the control of cell proliferation. Nat. Cell Biol. 2: E71-E72.

Tsukiyama-Kohara, K., Poulin, F., Kohara, M., DeMaria, C.T., Cheng, A., Wu, Z., Gingras, A.C., Katsume, A., Elchebly, M., Spiegelman, B.M., et al. 2001. Adipose tissue reduction in mice lacking the translational inhibitor 4E-BP1. Nat. Med. 7: 1128-1132.

Tuazon, P.T., Merrick, W.C., and Traugh, J.A. 1989. Comparative analysis of phosphorylation of translational initiation and elongation factors by seven protein kinases. I. Biol. Chem. 264: 2773-2777.

Ueki, K., Algenstaedt, P., Mauvais-Jarvis, F., and Kahn, C.R. 2000. Positive and negative regulation of phosphoinositide 3-kinase-dependent signaling pathways by three different gene products of the $\mathrm{p} 85 \alpha$ regulatory subunit. Mol. Cell. Biol. 20: 8035-8046.

van Slegtenhorst, M., de Hoogt, R., Hermans, C., Nellist, M., Janssen, B., Verhoef, S., Lindhout, D., van den Ouweland, A., Halley, D., Young, J., et al. 1997. Identification of the tuberous sclerosis gene TSC1 on chromosome 9q34. Science 277: 805-808.

van Slegtenhorst, M., Carr, E., Stoyanova, R., Kruger, W.D., and Henske, E.P. 2004. Tsc1+ and tsc2+ regulate arginine uptake and metabolism in Schizosaccharomyces pombe. I. Biol. Chem. 279: 12706-12713.

Verdu, J., Buratovich, M.A., Wilder, E.L., and Birnbaum, M.J. 1999. Cell-autonomous regulation of cell and organ growth in Drosophila by Akt/PKB. Nat. Cell. Biol. 1: 500-506.

Vivanco, I. and Sawyers. C.L. 2002. The phosphatidylinositol 3-Kinase AKT pathway in human cancer. Nat. Rev. Cancer 2: 489-501.

von Manteuffel, S.R., Gingras, A.C., Ming, X.F., Sonenberg, N., and Thomas, G. 1996. 4E-BP1 phosphorylation is mediated by the FRAP-p70s6k pathway and is independent of mitogen-activated protein kinase. Proc. Natl. Acad. Sci. 93: 4076-4080.

Waskiewicz, A.J., Flynn, A., Proud, C.G., and Cooper, J.A. 1997. Mitogen-activated protein kinases activate the serine/threonine kinases Mnk1 and Mnk2. EMBO J. 16: 1909-1920.

Wendel, H.G., De Stanchina, E., Fridman, J.S., Malina, A., Ray, S., Kogan, S., Cordon-Cardo, C., Pelletier, J., and Lowe, S.W. 2004. Survival signalling by Akt and eIF4E in oncogenesis and cancer therapy. Nature 428: 332-337.

Wienecke, R., Konig, A., and DeClue, J.E. 1995. Identification of tuberin, the tuberous sclerosis-2 product. Tuberin possesses specific Rap1GAP activity. J. Biol. Chem. 270: 16409-16414.

Wilson, K.F., Wu, W.J., and Cerione, R.A. 2000. Cde42 stimulates RNA splicing via the S6 kinase and a novel S6 kinase target, the nuclear cap-binding complex. J. Biol. Chem. 275: 37307-37310.

Xiao, G.H., Shoarinejad, F., Jin, F., Golemis, E.A., and Yeung, R.S. 1997. The tuberous sclerosis 2 gene product, tuberin, functions as a Rab5 GTPase activating protein (GAP) in modulating endocytosis. J. Biol. Chem. 272: 6097-6100.

Yamagata, K., Sanders, L.K., Kaufmann, W.E., Yee, W., Barnes, C.A., Nathans, D., and Worley, P.F. 1994. rheb, a growth factor- and synaptic activity-regulated gene, encodes a novel Ras-related protein. J. Biol. Chem. 269: 16333-16339.

Yanow, S.K., Manseau, F., Hislop, J., Castellucci, V.F., and Sossin, W.S. 1998. Biochemical pathways by which serotonin regulates translation in the nervous system of Aplysia. $J$. Neurochem. 70: 572-583.

Zaragoza, D., Ghavidel, A., Heitman, J., and Schultz, M.C. 1998. Rapamycin induces the $\mathrm{G}(0)$ program of transcriptional repression in yeast by interfering with the TOR signaling path- way. Mol. Cell. Biol. 18: 4463-4470.

Zhang, H., Stallock, J.P., Ng, J.C., Reinhard, C., and Neufeld, T.P. 2000. Regulation of cellular growth by the Drosophila target of rapamycin dTOR. Genes \& Dev. 14: 2712-2724.

Zhang, H., Cicchetti, G., Onda, H., Koon, H.B., Asrican, K., Bajraszewski, N., Vazquez, F., Carpenter, C.L., and Kwiatkowski, D.J. 2003a. Loss of Tsc1/Tsc2 activates mTOR and disrupts PI3K-Akt signaling through downregulation of PDGFR. J. Clin. Invest. 112: 1223-1233.

Zhang, Y., Gao, X., Saucedo, L.J., Ru, B., Edgar, B.A., and Pan, D. $2003 \mathrm{~b}$. Rheb is a direct target of the tuberous sclerosis tumour suppressor proteins. Nat. Cell. Biol. 5: 578-581. 


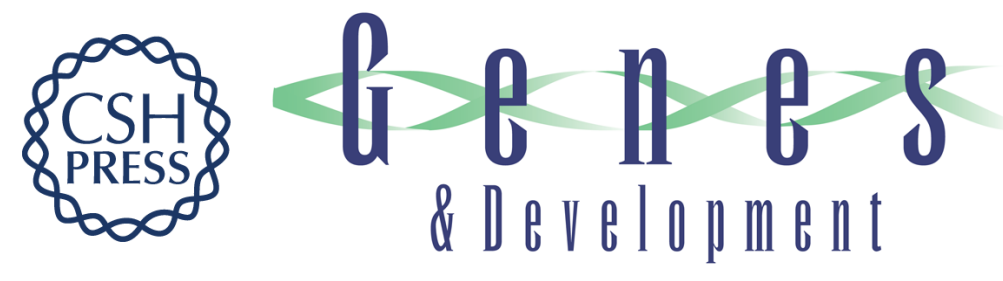

\section{Upstream and downstream of mTOR}

Nissim Hay and Nahum Sonenberg

Genes Dev. 2004, 18:

Access the most recent version at doi:10.1101/gad.1212704

References This article cites 210 articles, 116 of which can be accessed free at: http://genesdev.cshlp.org/content/18/16/1926.full.html\#ref-list-1

License

Email Alerting Receive free email alerts when new articles cite this article - sign up in the box at the top Service right corner of the article or click here.

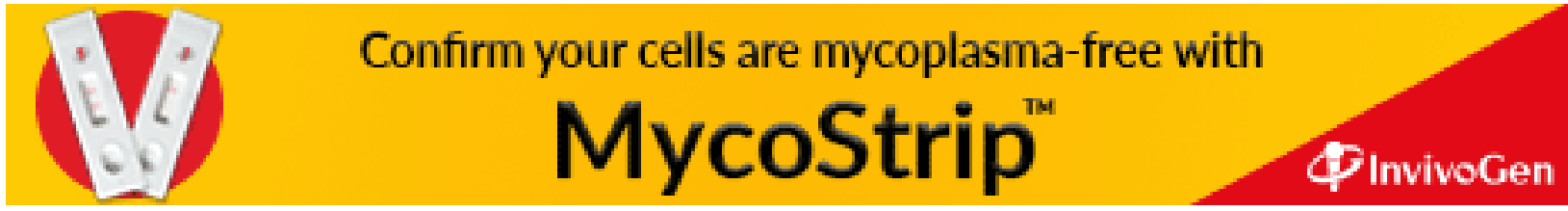

